INSTITUTO DE PESQUISAS ENERGÉTICAS E NUCLEARES

Autarquia Associada à Universidade de São Paulo

\title{
ESTUDO DO EFEITO DA RADIAÇÃO IONIZANTE POR FEIXE DE ELÉTRONS SOBRE O POLIETILENO DE ULTRA ALTO PESO MOLECULAR VIRGEM E RECICLADO INDUSTRIAL
}

\section{SALMO CORDEIRO DO ROSÁRIO}

Dissertação apresentada como parte dos requisitos para obtenção do Grau de Mestre em Ciências na Área de Tecnologia Nuclear - Aplicações

Orientador:

Dr. Leonardo Gondim de Andrade e Silva

São Paulo

2006 
Dedico este trabalho ao meu chefe e amigo Fernando José Gonçalves Ramos. 


\section{AGRADECIMENTOS}

Ao Prof. Dr. Leonardo Gondim de Andrade e Silva, pelo apoio, incentivo e paciência ao orientar-me na execução deste trabalho, apontando os caminhos que norteiam um estudo científico.

Ao Prof. Dr. Hélio Wiebeck pela preciosa ajuda e apoio na correta interpretação de dados e conceitos relativos à química dos polímeros.

Ao Instituto de Pesquisas Energéticas e Nucleares e ao Centro de Tecnologia das Radiações (CTR) pela oportunidade e apoio não só na realização deste trabalho, mas também por ter estimulado o meu crescimento intelectual em razão da convivência com os profissionais de alto nível que pertencem ao quadro de professores e técnicos deste Instituto.

À Braskem S.A., nas pessoas do Engo . Giancarlo Santana Roxo, Humberto Aragão, pelo apoio nos ensaios mecânicos e térmicos em seu laboratório e Enga . Ana Maria Liguori pelo incentivo inicial.

Ao Eng ${ }^{\circ}$. Maurice El Kalay da Ultra-Hi pelo fornecimento do material para confecção dos corpos-de-prova. 


\title{
ESTUDO DO EFEITO DA RADIAÇÃO IONIZANTE POR FEIXE DE ELÉTRONS SOBRE O POLIETILENO DE ULTRA ALTO PESO MOLECULAR VIRGEM E RECICLADO INDUSTRIAL
}

\author{
Salmo Cordeiro do Rosário
}

RESUMO

O polietileno de ultra alto peso molecular (UHMWPE) é um plástico de engenharia que tem várias aplicações atualmente, mormente em áreas específicas da indústria e da medicina. O UHMWPE pode ser utilizado ainda em outras aplicações: defensas portuárias; guias de corrente; revestimentos de caçambas, silos e calhas; engrenagens; buchas; guias de correias e próteses cirúrgicas. Esta gama de aplicações se deve ao fato das excelentes características técnicas que este material possui, como: alta resistência a abrasão, elevada resistência ao impacto, anti-aderência, atóxico, excelente resistência química, baixo peso específico, fácil usinagem e alta resistência a fadiga. Os tipos de polietileno de ultra alto peso molecular (UHMWPE) utilizados neste trabalho foram o UTEC 3041 e UTEC 6541 da Braskem. A reciclabilidade do UHMWPE ganhou interesse, porque a utilização desta matéria-prima na última década cresceu mais de 600\%, tornando-se um dos plásticos de engenharia mais utilizados para obtenção de peças usinadas depois da poliamida. Com o crescimento na utilização deste polímero na confecção de peças para maquinários, o seu desperdício tem sido muito grande, porque o resto deste material é desprezado, geralmente não sendo reaproveitado. Este trabalho tem como objetivo reciclar o UHMWPE UTEC 3041 e estudar as propriedades deste material virgem e reciclado e comparar os resultados entre si e com o UHMWPE UTEC 6541, e com estes materiais submetidos a diferentes doses de radiação. 


\title{
IONIZING RADIATION EFFECT STUDY BY ELECTRON BEAM ON ULTRA HIGH MOLECULAR WEIGHT POLYETHYLENE VIRGIN AND RECYCLED INDUSTRIAL
}

\author{
Salmo Cordeiro do Rosário
}

\begin{abstract}
Ultra High Molecular Weight Polyethylene (UHMWPE) is an engineering plastic which has several applications, chiefly, in specific areas of the industry and medicine. UHMWPE can be even for other applications such as: port fenders, current guide, bucket coating, silos and gutters, plugs, pulleys and surgical prosthesis. This range of applications is due to the excellent technical characteristics that this material owns, such as; high resistance to wear, high resistance to impact, anti-adherence, non toxic, excellent chemical resistance, low specific weight, easy mill processing, and high resistance to fatigue. The UHMWPE type used in this work were UTEC 3041 and UTEC 6541 of the Braskem. The recycling process of UHMWPE raised much interest, because the utilization of this rawmaterial grew over $600 \%$ in the last decade, becoming one of the most used engineering plastics for attainment of mill processed parts after polyamide. As the utilization of this polymer in the manufacturing of parts for machinery has grown, its waste is very big, because the rest of this material is thrown out, usually not being reused. The goal of this work is to recycle the UHMWPE UTEC 3041 and study the properties of this recycled and virgin material and compare the results between both with these materials submitted to different radiation dose.
\end{abstract}


Página

TABELA 1 - Resultados da resistência a abrasão do UHMWPE comparada a outros materiais

TABELA 2 - Resultados do teste de Taber do UHMWPE comparado com outros materiais

TABELA 3 - Perda de massa e aparência do UHMWPE a $22^{\circ} \mathrm{C}$ e $60^{\circ} \mathrm{C}$ em diferentes reagentes

TABELA 4 - Identificação do Pico FTIR

TABELA 5 - Resultados das propriedades do UHMWPE UTEC 3041 virgem e do UHMWPE UTEC 6541 virgem

TABELA 6 - Resultados das propriedades do UHMWPE UTEC 3041 reciclado e virgem

TABELA 7 - Resultados das propriedades do UHMWPE UTEC 3041 reciclado e do UHMWPE UTEC 6541 virgem

TABELA 8 - Resultados das propriedades do UHMWPE UTEC 3041 reciclado e do UHMWPE UTEC 3041 reciclado IR (100 kGy)

TABELA 9 - Resultados das propriedades do UHMWPE UTEC 3041 reciclado e do UHMWPE UTEC 3041 reciclado IR (300 kGy)

TABELA 10 - Resultados das propriedades do UHMWPE UTEC 3041 reciclado e do UHMWPE UTEC 3041 reciclado IR (500 kGy) 44

TABELA 11 - Resultados das propriedades do UHMWPE UTEC 3041 reciclado IR (100 kGy) e do UHMWPE UTEC 3041 virgem 46

TABELA 12 - Resultados das propriedades do UHMWPE UTEC 3041 reciclado IR (300 kGy) e do UHMWPE UTEC 3041 virgem $\quad 46$

TABELA 13 - Resultados das propriedades do UHMWPE UTEC 3041 reciclado IR (500 kGy) e do UHMWPE UTEC 3041 virgem

TABELA 14 - Resultados das propriedades do UHMWPE UTEC 3041 reciclado IR (100 kGy) e do UHMWPE UTEC 6541 virgem 
TABELA 15 - Resultados das propriedades do UHMWPE UTEC 3041 reciclado IR (300 kGy) e do UHMWPE UTEC 6541 virgem

TABELA 16 - Resultados das propriedades do UHMWPE UTEC 3041 reciclado IR (500 kGy) e do UHMWPE UTEC 6541 virgem

TABELA 17 - Resultados das propriedades do UHMWPE UTEC 3041 reciclado IR (100 kGy) e do UHMWPE UTEC 3041 virgem IR (100 kGy)

TABELA 18 - Resultados das propriedades do UHMWPE UTEC 3041 reciclado IR (300 kGy) e do UHMWPE UTEC 3041 virgem IR (300 kGy)

TABELA 19 - Resultados das propriedades do UHMWPE UTEC 3041 reciclado IR (500 kGy) e do UHMWPE UTEC 3041 virgem IR (500 kGy)

TABELA 20 - Resultados das propriedades do UHMWPE UTEC 3041 reciclado IR (100 kGy) e do UHMWPE UTEC 6541 virgem IR (100 kGy)

TABELA 21 - Resultados das propriedades do UHMWPE UTEC 3041 reciclado IR (300 kGy) e do UHMWPE UTEC 6541 virgem IR (300 kGy)

TABELA 22 - Resultados das propriedades do UHMWPE UTEC 3041 reciclado IR (500 kGy) e do UHMWPE UTEC 6541 virgem IR (500 kGy)

TABELA 23 - Resultados de DSC das amostras de UHMWPE UTEC 3041 virgem e reciclado e de UHMWPE UTEC 6541 virgem, não irradiado e irradiado, a diferentes doses 
Página

FIGURA 1 Dados do índice de abrasão para diferentes materiais

FIGURA 2 Dados da resistência ao impacto Izod para diferentes materiais

FIGURA 3 Micrografia escaneada do elétron do pó do UHMWPE antes da consolidação

FIGURA 4 Micrografia de transmissão do elétron do UHMWPE consolidado, mostrando as camadas

FIGURA 5 Análise de DSC para UHMWPE, mostrando as curvas endotérmica e exotérmica do primeiro aquecimento e o primeiro resfriamento

FIGURA 6 Gráfico de "FTIR" do UHMWPE irradiado a 15 Mrads e gama esterilizado no ar, com pico de chave de localização indicado

FIGURA 7 Picos de interesse na região marcada do espectro mostrado na Fig.6

FIGURA 8 Mudança de cor das amostras de UHMWPE UTEC 3041em função da dose de radiação 


\section{SUMÁRIO}

Página

1. INTRODUÇÃO 10

$\begin{array}{ll}\text { 2. OBJETIVO } & 13\end{array}$

3. JUSTIFICATIVA DO TRABALHO 14

4. REVISÃO BIBLIOGRÁFICA 15

4.1 Polietileno de Ultra Alto Peso Molecular (UHMWPE) 15

4.2 Aplicações do UHMWPE 16

4.3 Vantagens de peças fabricadas em UHMWPE em relação às $\begin{array}{ll}\text { peças de outros materiais } & 18\end{array}$

4.4 Formas de apresentação do UHMWPE $\quad 21$

$\begin{array}{ll}4.5 \text { Propriedades químicas do UHMWPE } & 21\end{array}$

4.6 Técnicas analíticas para avaliar os efeitos da radiação no UHMWPE 23

4.7 Modificação de Polímeros por Radiação Ionizante $\quad 31$

4.8 Irradiação com feixe de elétrons $\quad 32$

5. PARTE EXPERIMENTAL

$\begin{array}{ll}5.1 \text { Material } & 34\end{array}$

5.2 Reciclagem $\quad 34$

5.3 Preparação dos corpos-de-prova $\quad 34$

5.4 Irradiação das amostras $\quad 35$

5.5 Caracterização do material $\quad 35$

5.5.1 Determinação da tensão na ruptura 36

5.5.2 Determinação do alongamento na ruptura 36

5.5.3 Módulo secante a 1\% 37

$\begin{array}{ll}\text { 5.5.4 Densidade por empuxo } & 37\end{array}$

$\begin{array}{ll}\text { 5.5.5 Dureza (Shore D) } & 37\end{array}$

5.5.6 Impacto Charpy 38

5.5.7 Resistência à abrasão 38

5.5.8 Calorimetria Exploratória Diferencial (DSC) 38

6. RESULTADOS E DISCUSSÃO 40

6.1 Ensaios Físicos $\quad 40$

6.2 Calorimetria Exploratória Diferencial (DSC) 54

6.3 Efeito na coloração do UHMWPE, devido a radiação 55

$\begin{array}{ll}\text { 7. CONCLUSÕES } & 57\end{array}$

REFERÊNCIAS BIBLIOGRÁFICAS 


\section{1 - INTRODUÇÃO}

O polietileno é provavelmente o polímero que mais se vê na vida diária. É o plástico mais popular do mundo. Este é o polímero que há nas bolsas de armazém, nos frascos de xampu e de iogurtes, e inclusive nos coletes a prova de balas. Por ser um material tão versátil, tem uma estrutura muito simples, a mais simples de todos os polímeros comerciais. Uma molécula de polietileno não é nada mais que uma cadeia larga de átomos de carbono, com os átomos de hidrogênio unidos a cada átomo de carbono. Isso é que nos mostra à estrutura a continuação, somente com a cadeia de átomos de carbono, de mil átomos de longitude:

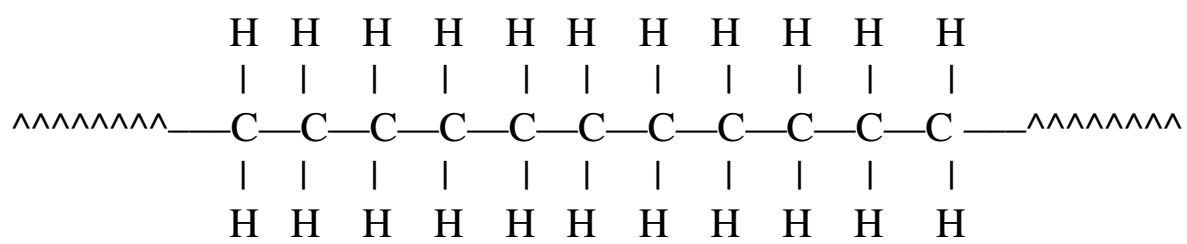

Estrutura do Polietileno

Em algumas ocasiões sua estrutura é um pouco mais complicada. Às vezes, alguns dos carbonos, em lugar de ter hidrogênios unidos a eles, têm associadas largas cadeias de polietileno. Isto se chama polietileno ramificado, que é o de baixa densidade, o LDPE. Quando há menos ramificação, se chama de alta densidade, o HDPE. O polietileno linear (sem ramificações) é muito mais forte que o polietileno ramificado, pois o polietileno ramificado é mais fácil de obter devido a polimerização simples e aleatória. O polietileno de ultra alto peso molecular (Ultra High Molecular Weight Polyethylene-UHMWPE), quase não tem ramificações, porém sua cadeia é muito longa.

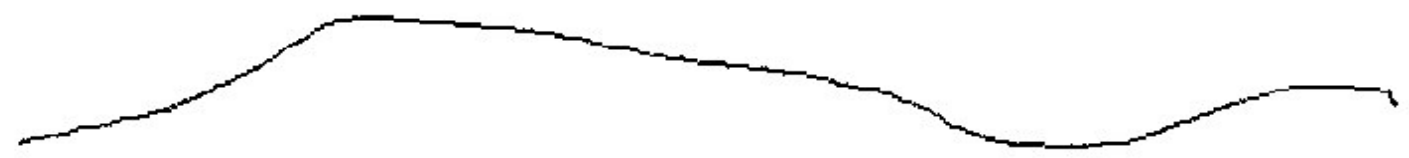

Molécula de polietileno linear 


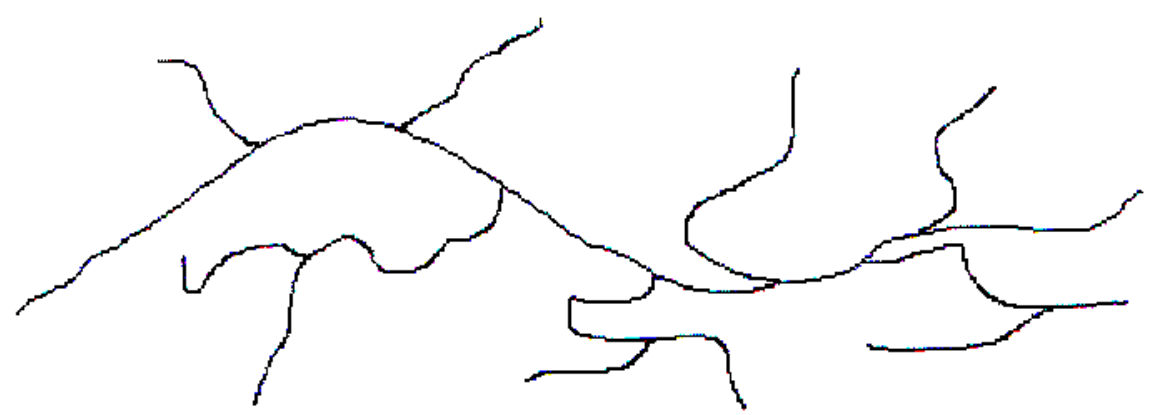

Molécula de polietileno ramificado ou LDPE

O polietileno linear possui normalmente massas molares numa faixa de 200.000 a 500.000 $\mathrm{g} / \mathrm{mol}$, mas pode ser maior. O polietileno com massas molares de três a oito milhões g/mol se denomina polietileno de ultra alto peso molecular (UHMWPE).

O UHMWPE pode ser utilizado para fazer fibras que são tão fortes que substituem as poliamidas aromáticas para uso em coletes a prova de balas. Também grandes lâminas de UHMWPE podem ser utilizadas em lugar de gelo em pistas de patinação.

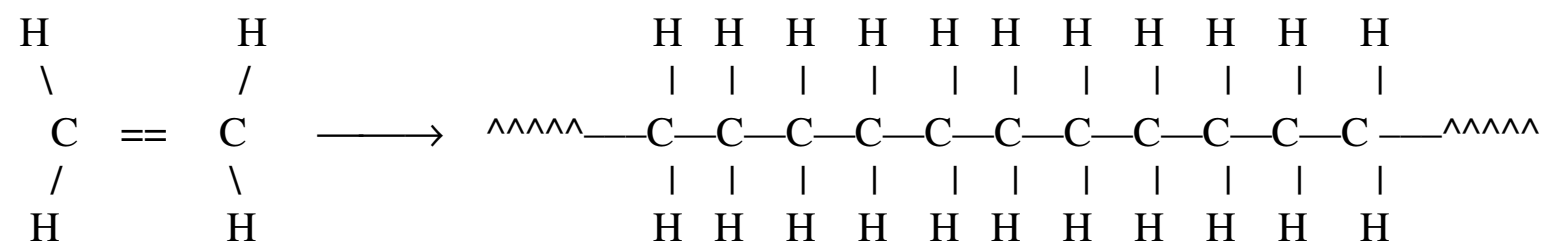

Estrutura molecular esquemática do Polietileno

O polietileno é um polímero vinílico, obtido a partir do monômero etileno.

$$
\mathrm{CH}_{2}=\mathrm{CH}_{2} \longrightarrow-\left[\mathrm{CH}_{2}-\mathrm{CH}_{2}\right]_{n}-
$$

O polietileno ramificado se obtêm por meio de uma polimerização vinílica por radicais livres. 
O polietileno linear se sintetiza por meio de um procedimento mais complicado chamado polimerização Ziegler-Natta. O UHMWPE se obtém empregando a polimerização catalizada por metalocenos.

O UHMWPE processado apresenta um conjunto próprio de características, que o faz superior aos outros termoplásticos quanto a: resistência a abrasão, resistência a fratura por impacto, resistência ao tensofissuramento, inércia química, baixíssimo coeficiente de atrito, auto lubrificação, absorção de ruídos e não absorção de água.

A massa molar extremamente alta do UHMWPE proporciona uma viscosidade tão elevada no estado fundido, que seu índice de fluidez se aproxima de zero, sendo assim é impossível processá-lo pelos métodos convencionais de injeção, sopro ou extrusão. Os métodos empregados no processo de fabricação do UHMWPE são os de compressão por termoprensagem, ou extrusão por pistão, por meio dos quais são obtidos chapas, blocos e tarugos semi-acabados para posterior acabamento por usinagem.

As tendências de utilização do UHMWPE estão crescendo de maneira bastante acentuada sendo que, nos últimos vinte anos houve um crescimento de mais de $600 \%$ em sua utilização em vários ramos industriais.

Com o crescimento da utilização deste polímero na confecção de peças para maquinários, o seu desperdício é muito grande, porque o resto deste material geralmente é jogado no lixo não sendo reaproveitável.

Neste trabalho não nos deteremos em detalhar os danos causados pelos plásticos no meio ambiente, por ser um tema já amplamente conhecido.

Do ponto de vista econômico, a perda do UHMWPE quando usado industrialmente é muito grande, uma vez que este material é muito caro. Assim sendo, surgiu a idéia de reciclar o UHMWPE de sobras industriais e posteriormente submetê-lo a ação da radiação para verificar se suas propriedades são recuperadas, uma vez que, o material ao sofrer reciclagem, geralmente pode perder propriedades. 


\section{2 - OBJETIVO}

Este trabalho tem como objetivo o estudo da reciclagem do UHMWPE e suas principais propriedades, abordando a sua reciclabilidade, focando o estudo das propriedades finais da resina reciclada, após submetida a radiação, comparando-se os resultados com o UHMWPE reciclado não irradiado e UHMWPE virgem não irradiado e irradiado.

Resumidamente, este trabalho consiste em:

Analisar as propriedades do UHMWPE com as aplicações que ele terá em sua forma final;

Comparar as propriedades dos dois tipos de UHMWPE: UTEC 3041 e UTEC 6541;

Comparar as propriedades do UHMWPE UTEC 3041 reciclado com o UHMWPE UTEC 3041 e o UTEC 6541 virgem;

Analisar o efeito da radiação nas propriedades do UHMWPE UTEC 3041 virgem e reciclado e do UTEC 6541 virgem;

Verificar a viabilidade da reciclagem do UHMWPE e

Analisar o efeito da radiação nas temperaturas de fusão e no grau de cristalinidade do UHMWPE. UTEC 3041 e do UHMWPE UTEC 6541. 


\section{3 - JUSTIFICATIVA DO TRABALHO}

Levando-se em conta que o mercado está em franca ascenção e a cada dia novas aplicações vêm surgindo devido a versatilidade do UHMWPE, além do fato que na indústria partes metálicas de atrito vem sendo substituídas em profusão, o que faz com que as aparas e as sobras de processo aumentem na mesma proporção; a reciclagem torna-se obrigatória e muito necessária.

Nos últimos anos foram encontrados na literatura alguns estudos sobre o efeito da radiação

gama no UHMWPE virgem ${ }^{1-11}$. Vale salientar contudo, que não foram encontrados estudos sobre reciclagem e irradiação do UHMWPE reciclado com feixe de elétrons, justificandose, assim, o desenvolvimento deste trabalho. 


\section{4 - REVISÃO BIBLIOGRÁFICA}

\section{1 - Polietileno de Ultra Alto Peso Molecular (UHMWPE)}

Nas Figuras 1 e 2 são mostrados, respectivamente, o excelente comportamento do índice de abrasão e da resistência ao impacto do UHMWPE em relação a outros materiais ${ }^{12}$.

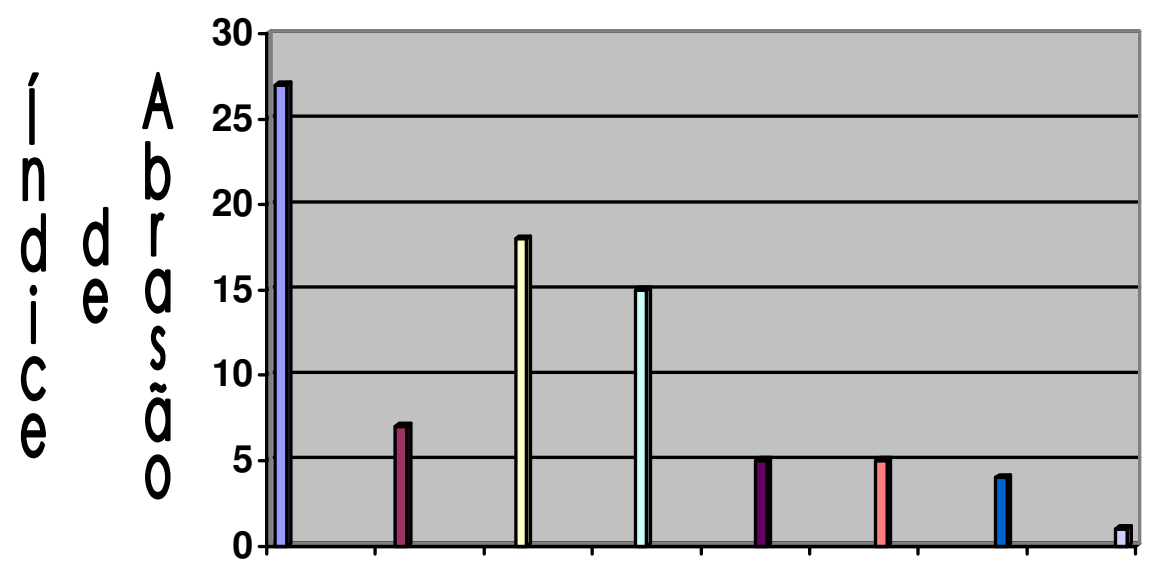

\begin{tabular}{|l|}
\hline पLATÃO \\
$\square$ AÇO CARBONO \\
$\square$ LAMINADO \\
$\square$ POLIACETAL \\
$\square$ POLIURETANO \\
$\square$ NYLON 6.6 \\
$\square$ NYLON 6 \\
$\square$ UHMWPE
\end{tabular}

FIGURA 1 - Dados do índice de abrasão para diferentes materiais
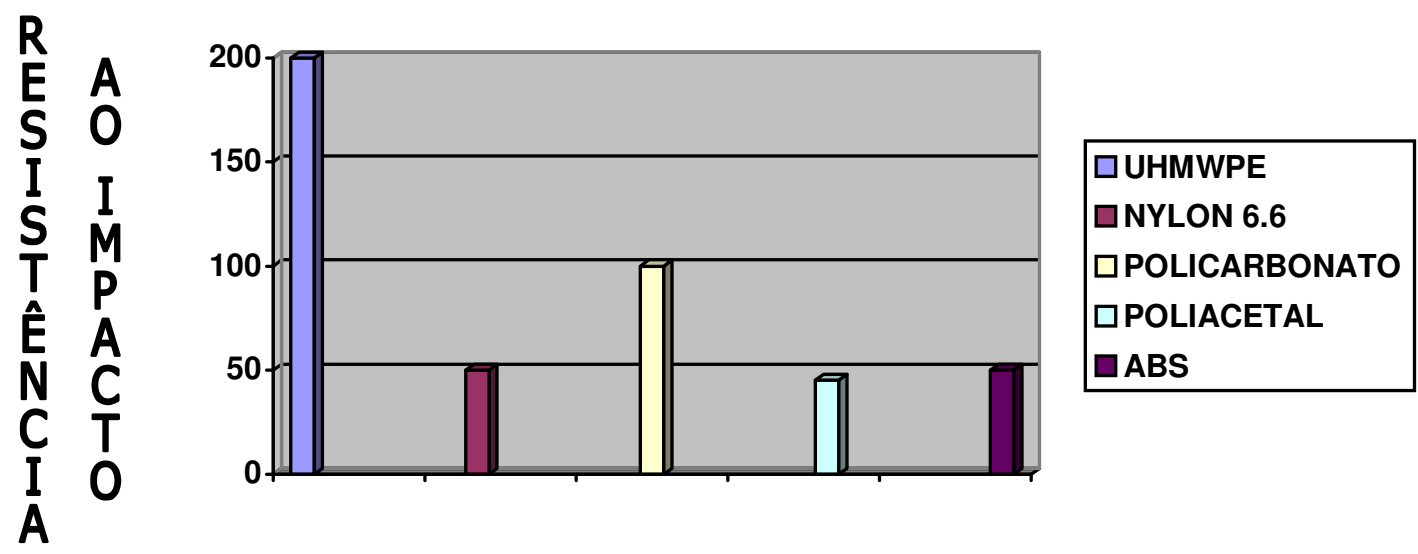

FIGURA 2 - Dados da resistência ao impacto Izod para diferentes materiais $\left(\mathrm{Kg} / \mathrm{cm}^{2}\right)$ 


\section{2 - Aplicações do UHMWPE ${ }^{13}$}

Como foi dito anteriormente, o UHMWPE tem uma versatilidade muito grande de aplicações.

\section{INDÚSTRIA DE PAPEL E CELULOSE}

É bastante usado no transporte de toras. As guias de UHMWPE têm uma durabilidade 5 vezes maior em relação as de aço (transportador de corrente). No caso do transportador de correia pode ser aplicado perfil de impacto ("low fric") de UHMWPE com borracha. Roletes de UHMWPE sem rolamentos apresentam um comportamento contra oxidação e travamentos.

Também pode ser usado para confecção de: mesa plana; réguas para "forming board", "hidro foil" e vácuo "foil"; réguas defletoras; coberturas para caixa de sucção (tampas), raspas de limpeza para rolos e prensas e em vedações para rolo de sucção. Para máquinas com velocidade até $250 \mathrm{~m} / \mathrm{min}$ é usado o UHMWPE com massa molar viscosimétrica maior que $5,0 \times 10^{6} \mathrm{~g} / \mathrm{mol}$.

Para máquinas com velocidade entre $250-400 \mathrm{~m} / \mathrm{min}$ é usado o UHMWPE com massa molar viscosimétrica com aditivo estabilizado ao calor.

Para máquinas com velocidade entre 400-800 m/min é usado o UHMWPE aditivado com cargas minerais.

Engrenagens dos cilindros secadores - material poliamida 6.6, reduz ruídos e elimina lubrificação.

\section{INDÚSTRIA PORTUÁRIA}

As defensas marítimas em UHMWPE possuem alta resistência ao desgaste por abrasão, excelente resistência ao impacto, resiste a quebra por pressão e possui baixo coeficiente de atrito, propiciando longa vida útil à defensa sem danos ao casco dos navios. O UHMWPE é modelado para revestimentos de silos, bicas, calhas em terminais de açúcar, grãos e sal. Também é utilizado como canecas para elevadores e roletes em poliamida 6.6. 
INDÚSTRIA ELETRO-ELETRÔNICA

É usado como "pallets" da linha de produção, berços e dispositivos, guia de corrente, pedra fluxadora para máquina de solda, rolamentos e buchas. O material usado é o UHMWPE AST - anti-estático com resistividade elétrica superficial (1,0 x 1,05 ohm.m).

\section{INDÚSTRIA ALIMENTÍCIA}

É usado como roscas e estrelas nas áreas de envasamento, guias, buchas, rolamentos, cilindros anti-aderentes, placa formadora de hambúrguer, "kibe", "nuguets", cortadores, dosadores, entre outros. O material utilizado é o UHMWPE atóxico.

\section{INDÚSTRIA DE BEBIDAS}

É usado como guias de corrente, perfis, curvas, roscas (caracol), guias entre estrelas, estrelas, guias de entrada e saída da lavadora e como buchas.

\section{MINERAÇÃO / CIMENTEIRAS}

É usado em revestimento de silos, calhas e bicas.

\section{GUIAS E PERFIS DE DESLIZAMENTOS}

Os perfis são produzidos com resina UHMWPE, material de alto desempenho e longa vida útil, possuindo excelente resistência ao desgaste, baixo coeficiente de atrito, autolubrificação, propiciando uma excelente relação custo x benefício não se comparando aos de polietileno de alta densidade de menor desempenho.

\section{GUIAS DE CORREIAS}

Sistemas transportadores utilizam em muitas ocasiões correias (planas, em "V" ou redondas) para transportar produtos e embalagens em linhas de produção. Para guiar e suportar estas correias existe uma linha de guias de correias em UHMWPE anti-estático, 
que evita o acúmulo de energia indesejável, gerado pelo atrito da borracha (correia) com o plástico (guia).

\section{GUIAS DE CORRENTES}

A utilização das guias de corrente em UHMWPE, notabilizam-se sobretudo nas aplicações onde a lubrificação é insuficiente, tanto em equipamentos onde o lubrificante pode contaminar os produtos manufaturados (alimentos, bebidas, tecidos, papéis, entre outros), como nos casos em que a lubrificação é difícil (longos trechos de correntes ou com dificuldade de acesso). Além disto, particularidades como: resistência ao desgaste, baixa absorção de umidade, resistência química, resistência ao impacto, redução de vibrações e ruídos, fazem do UHMWPE o material ideal para confecção das guias de correntes.

\section{PRÓTESES CIRÚRGICAS}

É de conhecimento geral a grande utilização deste polímero em aplicações de próteses cirúrgicas, devido as suas excelentes propriedades de resistência ao desgaste.

\section{3 - Vantagens de peças fabricadas em UHMWPE em relação às peças de outros materiais $^{14}$}

\section{SUPERFÍCIE DE BAIXA FRICÇÃO}

O baixo coeficiente de fricção do UHMWPE se aproxima do teflon, sua superfície limpa e auto lubrificada permite que partes móveis como bandas e cadeias se movam facilmente prevenindo contra o desgaste prematuro ou tendo que agregar tensão excessiva sobre componentes de muito valor. As superfícies recobertas de UHMWPE permitem o deslizamento suave e livre de materiais em pó ou aglomerados. Também evita que se maltratem ou raiem objetos como os vasilhames e outras embalagens. 


\section{RESISTÊNCIA AO DESGASTE}

A estrutura molecular do UHMWPE é inerentemente superior a resistência ao desgaste por fricção. Seu coeficiente é superior ao polietileno de alta densidade, poliamida e acetal. Os recobrimentos de UHMWPE protegem estruturas de muito valor contra o desgaste prematuro.

\section{RESISTÊNCIA AO IMPACTO}

O UHMWPE é o melhor substituto de muitos materiais que estão em contato com solavancos repentinos, golpes fortes, freqüentes ou constantes. Os materiais tradicionais se agridem, se astilham ou simplesmente apresentam fadiga. O UHMWPE é o único plástico que, quanto mais se golpeia, fica mais duro.

Nos testes de impacto utilizado a norma ASTM D-256 Izod o UHMWPE não se quebra, nem sequer a temperatura de congelamento.

\section{RESISTÊNCIA À CORROSÃO}

O UHMWPE resiste aos ataques químicos severos e não absorve umidade. É excelente para ser aplicado em ambientes cáusticos, água salgada, limpezas a vapor, entre outros. Mantém o maquinário em movimento sem bloqueios causados por bordas de metais corroídos.

Pode-se usar submergido em água (plantas de tratamentos de águas, processos químicos, entre outros), como também a temperatura de $-30^{\circ} \mathrm{C}$.

\section{CONTATO COM ALIMENTOS}

O UHMWPE cumpre com as regulamentações da FDA (Food and Drug Administration), para ser usado em processo de produtos alimentícios e farmacêuticos.

É fácil de usinar, porque se reduzem os "tempos ociosos" por reposição de partes do equipamento ao ser usinado. Seu trabalho é tão fácil como a madeira.

Por suas características de absorver impacto se consegue ter um maquinário mais silencioso. 


\section{PODER DIELÉTRICO}

É ideal para peças que são utilizadas em equipamentos elétricos ou eletromecânicos. Sua aplicação é segura em ambientes inflamáveis, explosivos ou altamente combustíveis por não gerar faíscas e além de tudo é auto-extingüível (resistividade elétrica superficial - 1,0 x 1,05 ohm.m).

\section{RESISTÊNCIA À ABRASÃO ${ }^{15}$}

A excelente resistência à abrasão do UHMWPE é demonstrada pelo Teste de Areia: amostras de materiais são mantidas a uma rotação constante de 1725 rpm, imersas em uma mistura de $50 \%$ de água e $50 \%$ de areia, durante 7 horas.

Os resultados da resistência a abrasão do UHMWPE obtidos em comparação a outros materiais são apresentados na Tabela 1 .

TABELA 1 - Resultados da resistência a abrasão do UHMWPE comparada a outros materiais $^{15}$

\begin{tabular}{lc}
\hline \multicolumn{1}{c}{ MATERIAL } & $\begin{array}{c}\text { PERDA DE MASSA RELATIVA } \\
(\text { AÇO 1018 }=100)\end{array}$ \\
\hline UHMWPE & 15 \\
Nylotec LM & 22 \\
Nylon Technyl & 31 \\
Poliuretano & 37 \\
PTFE & 72 \\
PEAD & 86 \\
Polytec 1000 & 110 \\
Polipropileno & 190 \\
Bronze & 190 \\
Celeron & 200 \\
\hline
\end{tabular}

A resistência à abrasão do UHMWPE é reafirmada pelos resultados do teste de Taber, que indica a perda de massa, em miligramas (método padrão de Taber). Os resultados deste teste do UHMWPE em comparação com outros materiais são apresentados na Tabela 2. 
TABELA 2 - Resultados do teste de Taber do UHMWPE comparado com outros materiais $^{15}$

\begin{tabular}{lc}
\hline \multicolumn{1}{c}{ MATERIAL } & $\begin{array}{c}\text { MASSA PERDIDA } \\
(\mathbf{m g})\end{array}$ \\
\hline UHMWPE & Nada \\
Poliuretano & 3 \\
Polietileno de alta densidade & 29 \\
PTFE & 42 \\
Borracha natural & 44 \\
Nylon 6.6 & 49 \\
Polietileno de baixa densidade & 70 \\
PVC de impacto normal & 160 \\
Borracha sintética & 205 \\
ABS & 275 \\
Poliestireno & 325 \\
\hline
\end{tabular}

\section{4 - Formas de apresentação do UHMWPE}

As apresentações disponíveis do UHMWPE são:

Barras cilíndricas sólidas,

Barras cilíndricas ocas (tubos ou bujões),

Placas e Lâminas,

Soleira,

Perfil.

\section{5 - Propriedades químicas do UHMWPE}

O UHMWPE tem elevada resistência química, como a maioria das poliolefinas, o que é confirmado pela Tabela 3. Na Tabela 3 é apresentada a perda de massa e a aparência de peças de teste de 0,040 × 1 × 2 polegadas, após imersão em reagentes sob determinadas condições. 
TABELA 3 - Perda de massa e aparência do UHMWPE a $22^{\circ} \mathrm{C}$ e $60^{\circ} \mathrm{C}$ em diferentes reagentes ${ }^{16}$.

\begin{tabular}{|c|c|c|c|c|c|c|}
\hline \multirow{2}{*}{$\begin{array}{l}\text { SUBSTÂNCIAS } \\
\text { QUÍMICAS } \\
\text { INORGÂNICAS }\end{array}$} & \multicolumn{3}{|c|}{$\begin{array}{c}22^{\circ} \mathrm{C} \\
\text { Perda de massa }\end{array}$} & \multicolumn{3}{|c|}{$\begin{array}{c}60^{\circ} \mathrm{C} \\
\text { Perda de massa }\end{array}$} \\
\hline & Dias & $\%$ & Aparência & Dias & $\%$ & Aparência \\
\hline \multirow{5}{*}{$\begin{array}{l}\text { Ácido clorossulfônico } \\
\text { Ácido crônico }(1 \mathrm{~N}) \\
\text { Ácido clorídrico, } 37 \% \\
\text { Peróxido de hidrogênio, } \\
30 \% \\
\text { lodo (em álcool) }\end{array}$} & 30 & --- & Decomposto & 10 & --- & Decomposto \\
\hline & 30 & $+0,34$ & Amarelo pálido & 10 & $-0,16$ & Amarelo pálido \\
\hline & 30 & $+0,24$ & Pardo leve & 10 & $+0,40$ & Pardo \\
\hline & 30 & $-0,01$ & Não foi atacado & 10 & $+0,04$ & Não foi atacado \\
\hline & 30 & $+1,78$ & Vermelho escuro & --- & --- & --- \\
\hline Ácido nítrico, $50 \%$ & 30 & $+0,78$ & Atacado, quebradiço & 10 & $+4,44$ & $\begin{array}{l}\text { Atacado, } \\
\text { quebradico }\end{array}$ \\
\hline Ácido fosfórico. 85\% & 30 & $+0,07$ & Não foi atacado & 10 & $+0,03$ & Não foi atacado \\
\hline Hidróxido de sódio & 30 & $-0,50$ & Não foi atacado & --- & --- & --- \\
\hline Hipoclorito de sódio & 30 & $+0,04$ & Não foi atacado & 10 & $+0,21$ & Não foi atacado \\
\hline $\begin{array}{l}\text { Ácido sulfúrico, } \\
\text { Fumegante }\end{array}$ & & $\begin{array}{l}\text { Decomposto } \\
\text { em um dia }\end{array}$ & $\begin{array}{l}\text { Decomposto } \\
\text { em um dia }\end{array}$ & --- & --- & 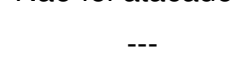 \\
\hline Ácido sulfúrico, $100 \%$ & 30 & $+0,25$ & Pouco atacado & 10 & $+1,00$ & Atacado, preto \\
\hline Ácido sulfúrico, $50 \%$ & 30 & $-0,06$ & Não foi atacado & 10 & $-1,14$ & Pouco atacado \\
\hline Água, água do mar & 03 & $+0,13$ & Não foi atacado & 10 & $+0,22$ & Não foi atacado \\
\hline
\end{tabular}

\section{ORGÂNICAS}

\begin{tabular}{|c|c|c|c|c|c|c|}
\hline Ácido acético & 30 & $+0,87$ & Marrom, pálido & 8 & $+0,83$ & Marrom, pálido \\
\hline Acetona & 30 & $+0,24$ & Não foi atacado & 4 & $+0,45$ & Não foi atacado \\
\hline Benzina & 30 & $+6,30$ & Pouco atacado & 4 & $+8,11$ & Pouco atacado \\
\hline Bissulfeto de carbono & 30 & $+16,2$ & Atacado, inchado & --- & --- & --- \\
\hline Tetracloreto de carbono & 30 & $+18,8$ & Atacado, inchado & 4 & $+22,4$ & Atacado, inchado \\
\hline Ciclohexanol & 30 & $-0,37$ & Não foi atacado & 8 & $+1,81$ & Pouco atacado \\
\hline Fetalto dibutil & 30 & $-0,36$ & Pouco atacado & 8 & $+0,95$ & Pouco atacado \\
\hline Etanol & 30 & $+0,03$ & Não foi atacado & 4 & $-0,01$ & Pouco atacado \\
\hline Acetato de etila & 30 & $+1,34$ & Pouco atacado & 4 & $+1,86$ & Pouco atacado \\
\hline Éter de etila & 30 & $+3,9$ & Pouco atacado & --- & --- & --- \\
\hline Dicloreto de etileno & 30 & $+12,2$ & Pouco atacado & --- & --- & --- \\
\hline Gasolina & 30 & $+4,81$ & Pouco atacado & 4 & $+6,61$ & Pouco atacado \\
\hline Gordura & & --- & & 7 & $+0,22$ & Não foi atacado \\
\hline Óleo de linhaça & 30 & $-0,70$ & Não foi atacado & 8 & $-0,23$ & Não foi atacado \\
\hline Óleo de oliva & 30 & $-0,50$ & Não foi atacado & 8 & $-0,12$ & Não foi atacado \\
\hline Éter de petróleo & 30 & $+5,74$ & Não foi atacado & --- & --- & --- \\
\hline Tolueno & 30 & $+7,0$ & Um pouco inchado & 8 & $+10,9$ & Um pouco inchado \\
\hline Tricloroetileno & 30 & $+15,0$ & Marrom inchado & 8 & $+26,3$ & Inchado \\
\hline Xileno & 30 & $+7,1$ & Um pouco inchado & 8 & $+15,5$ & Inchado \\
\hline
\end{tabular}




\section{6 - Técnicas analíticas para avaliar os efeitos da radiação no UHMWPE ${ }^{17}$}

A predominância do uso da radiação química para esterilização e melhoria no comportamento da utilização do UHMWPE tem levado a uma bateria de testes técnicos usados para quantificar rendimentos de dose, produtos derivados e propriedades morfológicas finais e mecânicas. Algumas destas técnicas têm sido padronizadas por meio dos comitês de avaliação da ASTM ou ISO, enquanto outras ainda estão com testes de análise mais aprimorados em andamento.

No processamento do UHMWPE o manufaturador inicia com o polietileno na forma de pó.

O pó é consolidado, moldado por extrusão ram, moldagem por compressão ou outra técnica menos comum como pressão isotática. A forma da amostra consolidada será uma prancha, barra ou implante pré-formado. Se a reticulação é desejada, o manufaturador sujeitará a amostra a radiação ionizante de uma fonte gama ou uma fonte de feixe de elétrons. Processos térmicos adicionais freqüentemente ocorrem para reduzir concentrações de radicais livres e subseqüente oxidação.

Em caso de implante é então transformado de um estoque irradiado depois que a esterilização adicional por meio da radiação gama, "eletron beam” ou óxido de etileno ocorra.

A continuação apresentaremos um sumário de técnicas comuns de testes usados hoje na indústria, e suas utilizações na análise do UHMWPE durante vários estágios do processo, incluindo análise de componentes recuperados.

\section{MORFOLOGIA $^{17}$}

A informação sobre a estrutura da cadeia do UHMWPE antes e depois da consolidação pode ser obtida por meio da microscopia eletrônica. O pó pré-consolidado pode ser analisado pela microscopia eletrônica de escaneamento por varredura ("SEM"), cujo exemplo é mostrado na Figura 3. 


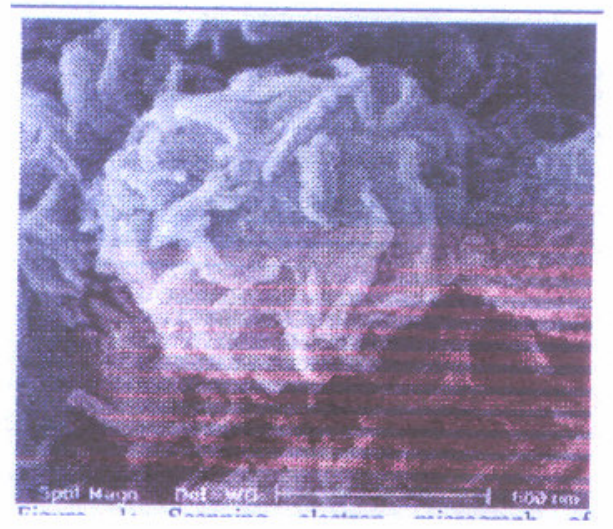

FIGURA 3 - Micrografia escaneada do elétron do pó do UHMWPE antes da consolidação

Mudanças na estrutura cristalina com consolidação e tratamento por radiação podem ser vistas com microscópio de transmissão eletrônico ("TEM"). Ao contrário da técnica de análise de superfície feita pela "SEM", a "TEM" tira a média espacial da morfologia dos polímeros, dependendo das diferenças na densidade eletrônica para estrutura do rendimento. Conseqüentemente, "microtoming" é requerido para rendimentos de 50-200 $\mathrm{nm}$ fatias grossas, as quais são então manchadas com ácido clorosulfúrico para realçar o contraste.

Um exemplo das lamelas em forma de fitas encontradas no UHMWPE é mostrado na Figura 4. Esta micrografia mostra lamelas primárias largas, com lamelas menores na intersecção. A espectroscopia de pequeno ângulo de raio X ("SAXS") é uma técnica quantitativa usada para examinar cristal espacial, tamanho do cristal e estrutura entrelaçada ${ }^{17}$. Esta técnica é de uso particular para determinar os efeitos de consolidação e desgaste na estrutura cristalizada na superfície e na massa da amostra. 


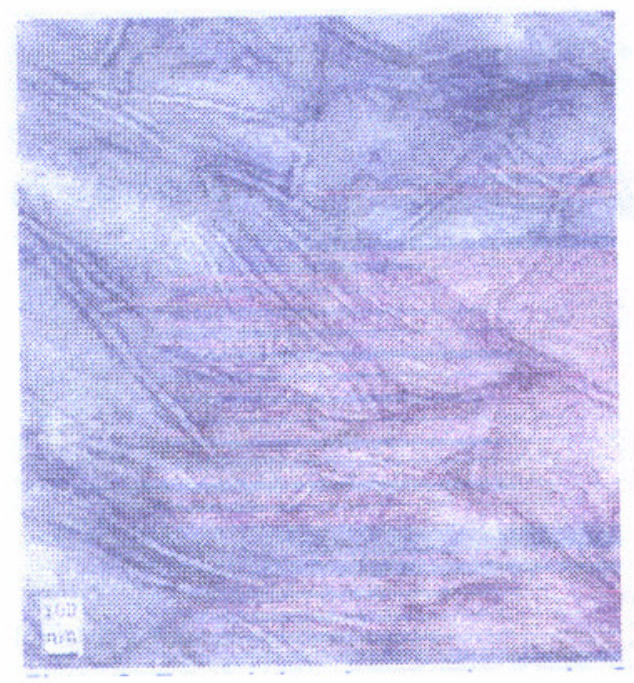

FIGURA 4 - Micrografia de transmissão do elétron do UHMWPE consolidado, mostrando as camadas

Informações quantitativas adicionais sobre cristalinidade e como ela se altera com o tratamento de radiação, pode ser obtida por calorimetria exploratória diferencial (DSC). Nesta técnica, uma amostra pequena de UHMWPE (5-10 mg) é selada numa câmara de alumínio para amostras, e posteriormente aquecida numa temperatura que varia desde a ambiente até $200^{\circ} \mathrm{C}$ com uma taxa de aquecimento de $10^{\circ} \mathrm{C} / \mathrm{min}$. Pelo monitoramento o fluxo aquecido requerido para manter esta variação de temperatura, eventos térmicos como transição vítrea e temperatura de fusão endotérmica podem ser monitorados.

Um gráfico típico de DSC para UHMWPE é mostrado na Figura 5. As linhas de construção mostradas são usadas para determinar o aquecimento total da fusão $\Delta \mathrm{H}$ (a área abaixo a endotérmica), e o início da temperatura de fusão (extrapolado do pico da temperatura de fusão) sabendo o total de aquecimento da fusão do UHMWPE $\left(\Delta \mathrm{H}_{\mathrm{f}}=291\right.$ $\mathrm{J} / \mathrm{g}$ ), a porcentagem de cristalinidade é computada como:

$$
\% \text { cristalinidade }=\frac{\Delta \mathrm{H}}{\Delta \mathrm{H}_{\mathrm{f}}} \times 100 \%
$$


Cuidados devem ser tomados no estabelecimento de linhas de construção para análise de cristalinidade. Sistemas com mais larga distribuição de tamanhos de cristais exibem uma larga faixa endotérmica, por isso a linha de construção deveria iniciar com temperaturas muito baixas (em torno de 25 a $40^{\circ} \mathrm{C}$ para capturar todo o aquecimento absorvido da fusão).

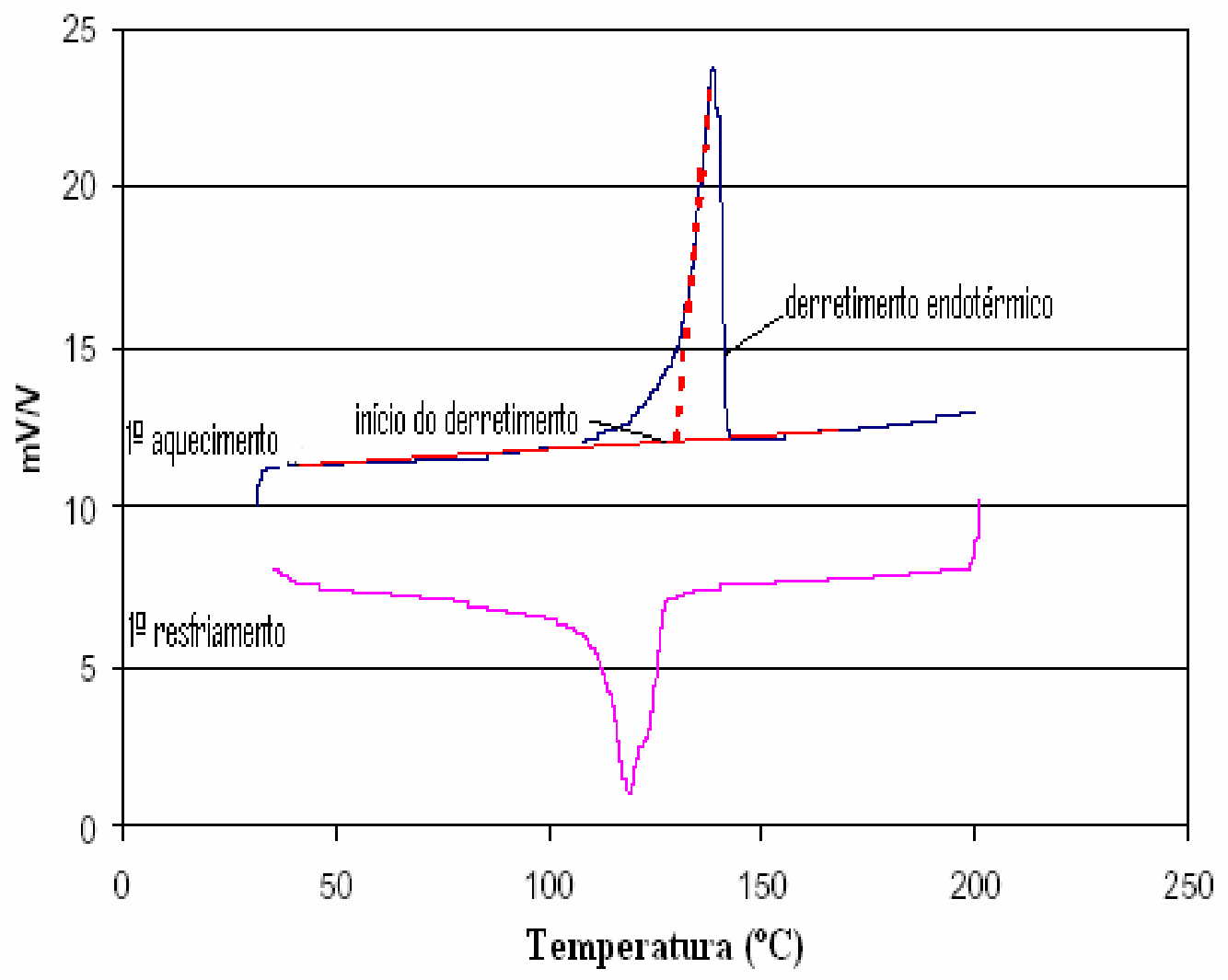

FIGURA 5 - Análise de DSC para UHMWPE, mostrando as curvas endotérmica e exotérmica do primeiro aquecimento e o primeiro resfriamento.

A construção das linhas mostra o cálculo da entalpia do derretimento $\Delta \mathrm{H}$ e pico da temperatura. 


\section{ANÁLISE QUÍMICA}

Em relação às mudanças na natureza química do UHMWPE com radiação, pesquisadores usualmente examinaram a massa molar e o espectro de absorção na região do infravermelho.

Antes da irradiação, a massa molar e a distribuição da massa molar são freqüentemente medidas, para que a eficácia da reação de "crosslinking" possa ser calculada a priori ${ }^{17}$, e mudanças na distribuição devido ao "crosslinking" (reticulação) ou craqueamento possa ser quantificada.

Duas técnicas são usadas para examinar a massa molar do UHMWPE, uma mais comum do que a outra. A diluição da solução viscosimétrica é a técnica mais comumente usada, conferindo rendimento a viscosidade intrínseca [ๆ]. Neste teste, o pó do UHMWPE é dissolvido em decahidronaftaleno a $140^{\circ} \mathrm{C}$, com um antioxidante recomendado, por uma hora, posteriormente é transferido de uma bureta aquecida para um viscosímetro Ubbelohde mantido a $135^{\circ} \mathrm{C}$. Pela medição dos tempos de dissolução da solução polimérica relativa para o solvente puro, e conhecendo os valores de calibração para o viscosímetro, a viscosidade intrínseca pode ser calculada. Por meio da relação entre tamanho da cadeia polimérica, que é proporcional a massa molar (assumindo não ramificado) e a interação polímero-solvente ${ }^{17}$, a média nominal da massa molar pode ser estimada como:

$$
\mathrm{M}_{\mathrm{w}, \text { nom. }}=5,37 \times 10^{4}[\mathrm{n}]^{1,37}
$$

Uma outra abordagem, chamada cromatografia de permeação de gel (GPC), permite determinar a distribuição da massa molar, ao invés de um único valor estatístico no momento. $\mathrm{Na}$ GPC, o polímero é dissolvido em triclorobenzeno a $160^{\circ} \mathrm{C}$, e é então forçado a passar por uma coluna contendo uma estrutura porosa que separa as cadeias poliméricas de acordo com o tamanho da cadeia. Um refratômetro posicionado no fim da coluna monitora a concentração do polímero em função do tempo, e, portanto o tamanho da cadeia. A GPC é a única técnica que fornece a distribuição das massas molares, a não ser que técnicas de fracionamento sejam empregadas. 
A precaução da GPC é que freqüentemente é difícil dissolver completamente o UHMWPE. Conseqüentemente, os componentes de maior massa molar são freqüentemente excluídos das análises.

\section{ESPECTROSCOPIA NO INFRAVERMELHO}

A espectroscopia no infravermelho com Transformada de Fourier (FTIR) tem se tornado uma das técnicas favoritas na análise dos efeitos da radiação ionizante no UHMWPE (espessura típica $100-200 \mu \mathrm{m}$ ). Muitos produtos radiolíticos são visíveis no espectro infravermelho e pode ser quantitativamente mensurado.

Erros adicionais são introduzidos quando a água está presente, que aparece como ruído na região de $1200-1800 \mathrm{~cm}^{-1}$. Purgando nitrogênio ou corrigindo o software para água, limpará o sinal espectral. Transmissão espectroscópica de filme fino pode freqüentemente resultar em ondulações no campo na região impressa (freqüências menores do que 1000 $\mathrm{cm}^{-1}$ ), o qual pode comprometer a análise quantitativa dos picos nestas regiões. Preparação cuidadosa de amostras podem prevenir o aparecimento de ondulações de campo ("Fourier rippling").

As freqüências chaves usadas para identificar produtos radiolíticos no UHMWPE são mostradas na Tabela 4. Exemplos de gráficos são mostrados nas Figura 6 e 7.

TABELA 4 - Identificação dos Picos FTIR do UHMWPE

\begin{tabular}{cc}
\hline Localização do Pico $\left[\mathrm{cm}^{-1}\right]$ & Descrição \\
\hline 910 & Grupos vinílicos Terminais relacionados a \\
965 & reticulação e craqueamento \\
1303 & Grupos transvinílicos relacionados com reticulação \\
1897 & Associado com regiões amorfas \\
1700 & Associado com regiões cristalinas \\
& Grupo carbonil, relacionados com oxidação \\
\hline
\end{tabular}

Numerosos estudos têm sido conduzidos para examinar a aparência dos grupos radiolíticos encontrados nos insertos de UHMWPE reticulados e esterilizados. 


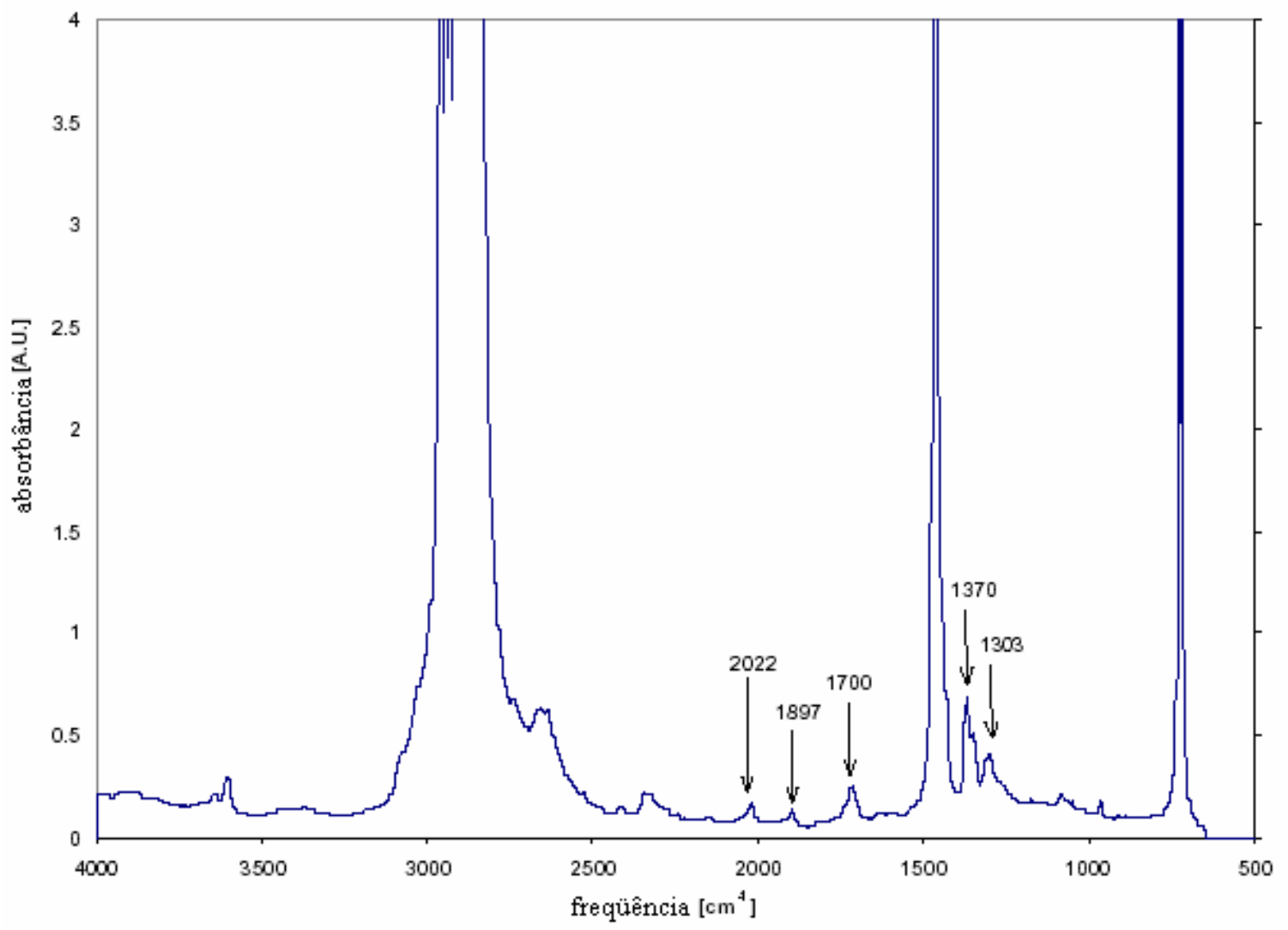

FIGURA 6 - Gráfico de "FTIR" do UHMWPE irradiado a 15 Mrads e gama esterilizado no ar, com pico de chave de localização indicado

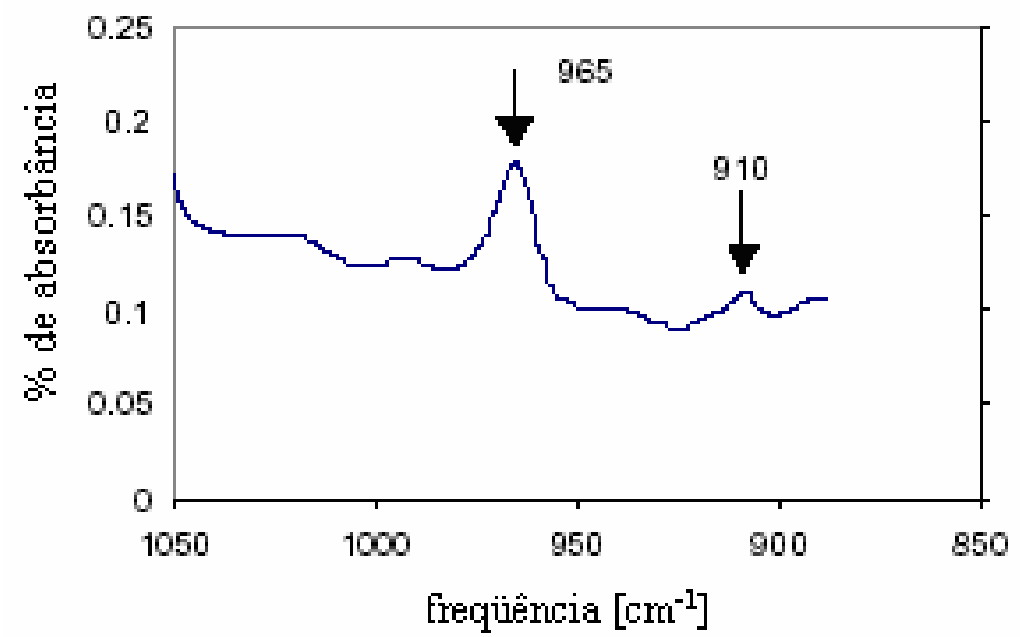

FIGURA 7 - Picos de interesse na região marcada do espectro mostrado na Fig. 6

Fonte: "Analytical Techniques for Assessing the Effects of Radiation on UHMWPE by Stephen Spiegelberg, Cambridge Polymer Group, Inc.”. 
O grupo predominante mais examinado é o grupo carbonil, que está associado com a oxidação $^{18-21}$.

O pico de oxidação da sub-superfície, tem sido bem documentado por muitos pesquisadores $^{22}$.

A reticulação e o rendimento transvinilideno foi estudado por muitos anos e mais recentemente pesquisadores têm utilizado a abordagem do uso de medidas do transvinilideno como um dosímetro interno para UHMWPE reticulado ${ }^{23-25}$.

Finalmente, a espectroscopia no infravermelho tem sido usada para quantificar o grau de cristalinidade no UHMWPE ${ }^{26,27}$. Pesquisadores encontraram uma relação linear entre o pico de absorção em $1897 \mathrm{~cm}^{-1}$ e a cristalinidade determinada por análise de raios X. Entretanto, os resultados são sensíveis para a estrutura química do polietileno examinado, em particular na presença de cadeia ramificada.

Não vamos nos estender neste tema, apesar de fascinante, pois o escopo da dissertação não é sobre técnicas de análises dos efeitos da radiação no UHMWPE, mas sim avaliação de propriedades físicas e mecânicas do UHMWPE reciclado após a irradiação. Entretanto, não poderíamos deixar de mencionar dois novos métodos.

Finalmente, dois métodos padrões têm surgido para antecipar a resposta de componentes implantados de UHMWPE em seres humanos. O envelhecimento acelerado, por meio do aumento de temperaturas e conteúdo de oxigênio, é usado em experimentos para prever níveis de oxidação por muitos anos de armazenamento ou em condições de uso humano $^{28,29}$.

Simuladores de quadris são usados para monitorar o comportamento de utilização sobre um modelo de utilização fisiologicamente exato ${ }^{30-32}$.

Estas duas abordagens são discutidas exaustivamente em outros manuscritos. Estas são algumas técnicas e testes disponíveis para que pesquisadores possam examinar o efeito de radiação no UHMWPE. 


\section{7 - Modificação de Polímeros por Radiação Ionizante}

Os polímeros são materiais orgânicos formados por unidades monoméricas repetidas (meros) que apresentam elevada massa molar. Algumas modificações nas propriedades químicas e físicas, tais como elétricas, mecânicas e térmicas dos polímeros são observadas em decorrência das interações da radiação com os mesmos, acarretando uma mudança na sua estrutura.

As radiações ionizantes ao interagirem com o material, transferem energia ao material, provocando excitação e ionização das moléculas, o que pode produzir modificações permanentes na estrutura físico-química do polímero. Durante o processo de irradiação, a energia absorvida poderá ser distribuída ao longo da cadeia polimérica.

A irradiação de polímeros é utilizada pelas indústrias para modificar polímeros por meio da reticulação e da cisão da cadeia polimérica, e da enxertia (para a produção de polímeros enxertados).

Os dois efeitos principais em um polímero submetido à radiação são ${ }^{33,34}$ :

- Cisão da cadeia principal ocorrendo um rompimento aleatório (randômico) das ligações C-C da cadeia principal, o qual reduz a massa molar do polímero, promovendo a formação de gases e insaturações, com a perda das propriedades mecânicas. O local onde ocorrerá a cisão será determinado pela estereoquímica, pelo grau de cristalinidade e pela energia de dissociação das ligações dos grupos contidos no polímero. Este processo é conhecido como degradação.

- Reticulação (crosslinking) que resulta na formação de várias ligações cruzadas (rede tridimensional insolúvel), com o aumento da massa molar do polímero. A reticulação é um processo por meio do qual duas cadeias poliméricas tornam-se unidas por meio de uma ligação covalente ou de uma outra molécula ou radicais, resultando em um acréscimo na massa molar média do polímero, podendo resultar na melhoria de suas propriedades químicas, físicas, térmicas e mecânicas. 
Os aspectos que influenciam no efeito da radiação em polímeros, levando a predominância da cisão, reticulação ou de ambas, estão relacionados com a estrutura química do polímero, morfologia, grau de cristalinidade, estado em que se encontra o polímero durante a irradiação, atmosfera da irradiação, entre outros ${ }^{35}$.

Portanto, os efeitos da radiação em polímeros é resultado de uma seqüência de eventos que podem ser divididos em: físico (energia absorvida e transferida), físico-químico (ionização e excitação) e químico (radicais, moléculas ionizadas, reações radical-radical e reações iônicas), os quais ocasionam alterações morfológicas estruturais e consequientemente mudanças nas propriedades dos materiais.

\section{8 - Irradiação com feixe de elétrons}

Neste trabalho as irradiações das amostras foram realizadas com feixe de elétrons proveniente de um acelerador linear de elétrons.

A utilização de acelerador de elétrons como fonte de radiação oferece vantagens em relação a fontes de radioisótopos. Estas vantagens podem ser resumidas no custo operacional baixo e na produção de feixe de energia alta (permitindo que filmes e outros materiais de espessura fina sejam processados em alta velocidade). A segurança que um acelerador de elétrons oferece é uma vantagem adicional, quando a máquina aceleradora de elétrons está desligada não há radiação residual ${ }^{36}$.

Os aceleradores de elétrons são muito utilizados no processamento industrial para modificação de polímeros (contração de tubos e filmes, radiação de fios e cabos, vulcanização de borracha), polimerização de superfície (curas de resinas, adesivos e tintas) e esterilização (área médica e alimentos) ${ }^{36,37}$.

Os aceleradores utilizados em processos industriais produzem elétrons na faixa de energia de 0,5 a $10 \mathrm{MeV}$ e este feixe de elétrons pode ser obtido pelo processo direto ou indireto ${ }^{38}$.

A produção de feixe de elétrons pelo processo direto é obtida por um filamento de tungstênio que fornece elétrons para um tubo de aceleração a vácuo. Esse tubo é formado 
por uma série de eletrodos polarizados com tensões contínuas, fazendo os elétrons adquirirem energia cinética e atingirem a câmara de varredura que os dispersa, formando, assim, um feixe de elétrons ${ }^{39}$.

No processo indireto, os elétrons provenientes de um emissor termoiônico são injetados em pequenos pulsos por meio de cavidades ressonantes a vácuo, que servem como guia de onda, produzindo uma radiação eletromagnética interna de rádio-frequiência (RF).

Os elétrons absorvem a energia do campo eletromagnético oscilante na cavidade. Este tipo de equipamento fornece elétrons com energias entre 10 e $30 \mathrm{MeV}^{39}$.

A irradiação com feixe de elétrons começou a ser utilizada na década de 50, mas somente nos últimos 10 anos vem se desenvolvendo com mais ênfase ${ }^{36}$. 


\section{1 - Material}

Os polietilenos de UHMWPE utilizados neste trabalho são da Empresa Braskem (Camaçari-BA) e os materiais reciclados foram fornecidos pela Ultra-Hi (Barueri-SP). Utilizou-se o UHMWPE UTEC 3041 virgem que é um dos mais utilizados na indústria brasileira, com massa molar de cerca de 3 milhões de g/mol, sendo recomendado para aplicações onde a exigência a resistência ao impacto é maior que a exigência de resistência a abrasão. Outro "grade" de UHMWPE que foi testado foi o UHMWPE UTEC 6541, que é um polietileno de ultra alta massa molar, com cerca de 8 milhões de $\mathrm{g} / \mathrm{mol}$, onde as propriedades de abrasão são superiores as de impacto e portanto recomenda-se para aplicações onde a necessidade de superfície deslizante é maior que a resistência ao impacto.

\section{2 - Reciclagem}

Neste trabalho utilizou-se a reciclagem mecânica de resíduos industriais do UHMWPE UTEC 3041, portanto as etapas de lavagem e secagem não foram realizadas. A reciclagem do UHMWPE foi realizada utilizando um moinho de baixa rotação de 20 a $30 \mathrm{rpm}$ especial para reciclagem mecânica. Após a obtenção de partículas de aproximadamente 0,5 a 1,0 $\mathrm{cm}^{2}$, o material foi transportado para um micronizador que teve como objetivo reduzir o UHMWPE reciclado em partículas muito pequenas quase como pó. Ambos os moinhos de baixa rotação e o micronizador foram refrigerados à água, para que não ocorresse o super aquecimento do UHMWPE nas lâminas do moinho, evitando o empastamento do material e, portanto a formação de grumos.

\section{3 - Preparação dos corpos-de-prova}

Os corpos-de-prova de todas as amostras foram confeccionados no laboratório da Braskem seguindo as normas necessárias de acordo com o ensaio a ser realizado. Na confecção dos mesmos foi usado o processo de moldagem por compressão. A massa molar extremamente elevada do UHMWPE UTEC 3041 proporciona uma viscosidade muito alta no estado 
fundido, portanto seu índice de fluidez a $190^{\circ} \mathrm{C} / 21,6 \mathrm{Kg}$ se aproxima de zero. Assim não foi possível processá-lo por métodos convencionais de injeção, sopro ou extrusão. Neste caso foram obtidos semi-acabados, em forma de chapas para acabamento posterior por usinagem. Para obtenção dos corpos-de-prova utilizou-se uma prensa hidráulica com capacidade de exercer pressão mínima de $70 \mathrm{Kg} / \mathrm{cm}^{2}$ sobre a área projetada da chapa, que posteriormente foi usinada. A temperatura máxima foi de $220^{\circ} \mathrm{C}$ aproximadamente. $\mathrm{O}$ molde foi dimensionado para suportar $70 \mathrm{Kgf} / \mathrm{cm}^{2}$, com um bom fator de segurança, e foi previsto canais de aquecimento e resfriamento. Para chapas com espessuras superiores a 20 $\mathrm{mm}$, foi mantido o controle de temperatura das partes superior e inferior da chapa. Isso foi necessário para prevenir resfriamento prematuro, na periferia que causaria formação de uma casca sólida na chapa. A folga entre o macho e a fêmea de 3 a $5 \mathrm{~mm}$ foi suficiente, visto que o UHMWPE não escoa no estado fundido. $\mathrm{O}$ acabamento da superfície do molde dependeu das necessidades da chapa. Apesar de o molde ser polido utilizou-se um desmoldante (pó de estearato para facilitar a desmoldagem). Para cálculo de quantidade de pó utilizado, levou-se em consideração a diferença de densidade entre o pó $\left(\sim 0,40 \mathrm{~g} / \mathrm{cm}^{3}\right)$ e o material fundido $\left(\sim 0,95 / \mathrm{cm}^{3}\right)$. Utilizou-se equipamentos auxiliares como balança para pesar o material, misturador para adicionar pigmentos ou aditivos e rodo e réguas para acertar a espessura do pó no molde ${ }^{40}$.

\section{4 - Irradiação das amostras}

Após a preparação dos corpos-de-prova alguns deles foram irradiados com feixe de elétrons proveniente de acelerador de elétrons tipo Dynamitron, da Radiation Dynamics, modelo DC 1500-JOB 188 com energia máxima de 1,5 MeV e corrente de feixe variando de 0,3 mA a $25 \mathrm{~mA}$ do CTR (Centro de Tecnologia das Radiações-IPEN-CNEN/SP). As doses de radiação aplicadas as amostras virgens e recicladas foram de 100, 300 e 500 kGy com uma taxa de dose de 22,61 kGy/s.

\section{5 - Caracterização do material}

Posteriormente, tanto as amostras virgens e recicladas, irradiadas e não irradiadas foram submetidas a diferentes ensaios seguindo as normas pertinentes a cada um deles. 
Foram realizados os ensaios de tensão na ruptura; alongamento na ruptura; módulo secante ou de elasticidade; densidade por empuxo; dureza (Shore D); impacto Charpy com duplo entalhe a $23^{\circ} \mathrm{C}$; índice de abrasão e calorimetria exploratória diferencial (DSC).

\subsection{1 - Determinação da tensão na ruptura (MPa)}

O objetivo do teste é determinar a resistência à tração das diferentes amostras de UHMWPE virgem e reciclada, não irradiadas e irradiadas.

A tensão de ruptura é avaliada pela carga máxima suportada pelo material por unidade de área, no momento da ruptura.

Este teste mede a resistência mecânica do material, portanto, quanto maior for a tensão, maior será a carga suportada pelo material. A tensão é calculada dividindo-se a força pela área na qual atua e é expressa em $\mathrm{Kgf} / \mathrm{cm}^{2}$ ou $\mathrm{MPa}$.

A norma utilizada para realização deste teste foi a ASTM D- $638^{41}$.

\subsection{2 - Determinação do alongamento na ruptura (\%)}

O objetivo do teste é determinar o alongamento das diferentes amostras de UHMWPE virgem e reciclada, não irradiadas e irradiadas.

O alongamento na ruptura representa o aumento percentual (\%) do comprimento da peça (corpo-de-prova) sob tração no momento da ruptura.

A norma utilizada para realização deste teste foi a ASTM D-638 ${ }^{41}$. 


\subsection{3 - Módulo secante a $1 \%$ (MPa)}

O objetivo do teste é determinar o módulo elástico em tração (tensão), ou seja a resistência à carga que o material suporta, sua rigidez quando submetido a esforço e sua deformação elástica antes de atingir a zona plástica (deformação permanente), das diferentes amostras de UHMWPE virgem e reciclada, não irradiadas e irradiadas.

A norma utilizada para realização deste teste foi a ASTM D-638 ${ }^{41}$.

\subsection{4 - Densidade por empuxo $\left(\mathrm{g} / \mathrm{cm}^{3}\right)$}

O objetivo do teste é determinar a densidade das diferentes amostras de UHMWPE virgem e reciclada, não irradiadas e irradiadas.

A densidade representa a relação da massa versus volume da amostra estudada. A densidade foi determinada pelo deslocamento da água.

A norma utilizada para realização deste teste foi a ASTM D-792 $2^{42}$.

\subsection{5 - Dureza (Shore D)}

O objetivo do teste é determinar a dureza das diferentes amostras de UHMWPE virgem e reciclada, não irradiadas e irradiadas.

A dureza pode ser definida pela resistência da superfície do material à penetração. A dureza e a resistência à tração estão intimamente ligadas.

A norma utilizada para realização deste teste foi a ASTM D-2240 ${ }^{43}$. 


\subsection{6 - Impacto Charpy $23^{\circ} \mathrm{C}\left(\mathrm{KJ} / \mathrm{m}^{2}\right)$}

O objetivo do teste é determinar a resistência ao impacto Charpy das diferentes amostras de UHMWPE virgem e reciclada, não irradiadas e irradiadas.

A resistência ao impacto representa a tenacidade ou a resistência de um material rígido à deformação a uma velocidade alta, conseqüentemente, indica a capacidade do material absorver energia quando uma força é aplicada rapidamente.

A tenacidade é definida como a energia necessária para romper o material, portanto, quanto maior a resistência ao impacto de um material, maior é a sua ductibilidade.

A norma utilizada para realização deste teste foi a ISO $11542-2 b^{44}$.

\subsection{7 - Resistência à abrasão}

O objetivo do teste é determinar a quantidade de massa perdida, quando o material (corpode-prova) é friccionado (atritado) em ambiente arenoso 50\% e 50\% água, durante 7 horas a $1725 \mathrm{rpm}$.

Este teste é comparativo com relação a outros materiais como uma placa de aço 1018 que assume um valor 100 como referência, como foi apresentado na Tabela 1.

A norma utilizada para realização deste teste foi a NBR $14922^{45}$.

\subsection{8 - Calorimetria Exploratória Diferencial (DSC)}

A Calorimetria Exploratória Diferencial (DSC) é uma técnica que mede a quantidade de calor envolvido com as correspondentes temperaturas das transições físico-químicas. DSC mede a diferença de energia fornecida à substância e a um material de referência, ambos 
submetidos à mesma programação controlada de temperatura, de modo que a amostra e a referência sejam mantidas em condições isotérmicas uma em relação à outra ${ }^{46,47}$.

A técnica DSC é muito utilizada na caracterização de polímeros e pode ser empregada na medição das temperaturas de transição vítrea, fusão e cristalização, determinação da cristalinidade, medição de calor específico e degradação térmica e oxidativa ${ }^{48}$.

Nos materiais semicristalinos, especialmente os que têm um grau de cristalinidade alta, a temperatura de transição vítrea $(\mathrm{Tg})$ normalmente é imperceptível por esta técnica.

A norma utilizada para realização deste teste foi a ASTM D 3418-82 49 .

Os ensaios de calorimetria exploratória diferencial (DSC) foram realizados no Laboratório de Análise Térmica da Braskem - BA, utilizando equipamento TA Instrument modelo DSC 2910, em atmosfera dinâmica de ar sintético e de nitrogênio puro, respectivamente, com um fluxo de $50 \mathrm{ml} / \mathrm{min}$. Cada amostra foi submetida a três experimentos e nas duas técnicas utilizou-se taxa de aquecimento de $10^{\circ} \mathrm{C} /$ minuto; as massas das atmosferas foram de aproximadamente $6 \mathrm{mg}$. 


\section{6 - RESULTADOS E DISCUSSÃO}

\section{1 - Ensaios Físicos}

As análises foram feitas comparando os resultados entre os diferentes tipos de amostras:

1. UHMWPE UTEC 3041 virgem $\mathrm{x}$ UHMWPE UTEC 6541 virgem

2. UHMWPE UTEC 3041 reciclado $x$ UHMWPE UTEC 3041 virgem

3. UHMWPE UTEC 3041 reciclado x UHMWPE UTEC 6541 virgem

4. UHMWPE UTEC 3041 reciclado $x$ UHMWPE UTEC 3041 reciclado Irradiado (IR)

5. UHMWPE UTEC 3041 reciclado IR x UHMWPE UTEC 3041 virgem

6. UHMWPE UTEC 3041 reciclado IR x UHMWPE UTEC 6541 virgem

7. UHMWPE UTEC 3041 reciclado IR x UHMWPE UTEC 3041 virgem IR

8. UHMWPE UTEC 3041 reciclado IR x UHMWPE UTEC 6541 virgem IR

1) UHMWPE UTEC 3041 virgem $x$ UHMWPE UTEC 6541 virgem

$\mathrm{Na}$ Tabela 5 são apresentados os resultados das propriedades do UHMWPE UTEC 3041 virgem e do UHMWPE UTEC 6541 virgem.

TABELA 5 - Resultados das propriedades do UHMWPE UTEC 3041 virgem e do UHMWPE UTEC 6541 virgem.

\begin{tabular}{|c|c|c|}
\hline Propriedades & UTEC 3041 virgem & UTEC 6541 virgem \\
\hline Tensão na ruptura (MPa) & 28,4 & 28,5 \\
\hline Alongamento na ruptura (\%) & 248,0 & 200,0 \\
\hline Densidade por empuxo $\left(\mathrm{g} / \mathrm{cm}^{3}\right)$ & $\mathbf{0 , 9 3 0}$ & 0,929 \\
\hline Dureza (Shore D) & 64 & 65 \\
\hline Impacto Charpy $23^{\circ} \mathrm{C}\left(\mathrm{KJ} / \mathrm{m}^{2}\right)$ & 185,3 & 84,9 \\
\hline Módulo Secante à 1\% (MPa) & 703,9 & 699,7 \\
\hline Índice de Abrasão & 25 & 21 \\
\hline
\end{tabular}


A diferença básica entre estes dois "grades" de UHMWPE é a massa molar, que no UTEC 3041 é da ordem de 3 milhões de g/mol e o do UTEC 6541 é da ordem de 8 milhões de $\mathrm{g} / \mathrm{mol}^{40}$. Isto pode ser observado analisando as propriedades de cada tipo. No alongamento na ruptura observa-se uma predominância do UTEC 3041 virgem sobre o UTEC 6541 virgem, porque o UTEC 3041 por ter uma cadeia mais curta ele se alonga mais quando tracionado do que o UTEC 6541 que se rompe mais facilmente quando submetido ao mesmo esforço. Não se nota quase mudança na densidade e na dureza devido a ambos os materiais terem o mesmo grau de cristalinidade (compactação molecular). $\mathrm{Na}$ resistência ao impacto, todavia a diferença entre estes dois tipos se acentua, conferindolhes características e aplicações diferenciadas. Analogamente ao alongamento na ruptura, a resistência ao impacto é superior no UTEC 3041 devido a sua cadeia ser mais curta, oferecendo mais resistência na quebra do que o UTEC 6541 de cadeia longa e, portanto mais frágil. No módulo secante não se observa diferença significativa. A resistência a abrasão do UTEC 3041 é menor que o UTEC 6541.

\section{2) UHMWPE UTEC 3041 reciclado x UHMWPE UTEC 3041 virgem}

Na Tabela 6 são apresentados os resultados das propriedades do UHMWPE UTEC 3041 reciclado e virgem.

TABELA 6 - Resultados das propriedades do UHMWPE UTEC 3041 reciclado e virgem

\begin{tabular}{|c|c|c|}
\hline Propriedades & UTEC 3041 reciclado & UTEC 3041 virgem \\
\hline Tensão na ruptura (MPa) & 20,8 & 28,4 \\
\hline Alongamento na ruptura (\%) & 121,8 & 248,0 \\
\hline Densidade por empuxo $\left(\mathrm{g} / \mathrm{cm}^{3}\right)$ & 0,933 & 0,930 \\
\hline Dureza (Shore D) & 65 & 64 \\
\hline Impacto Charpy $23^{\circ} \mathrm{C}\left(\mathrm{KJ} / \mathrm{m}^{2}\right)$ & 107,8 & 185,3 \\
\hline Módulo Secante à $1 \%$ (MPa) & 709,9 & 703,9 \\
\hline Índice de Abrasão & 24 & 25 \\
\hline
\end{tabular}

De acordo com os resultados apresentados na Tabela 6 observa-se que na tensão na ruptura ocorreu uma perda de 26,24\% do reciclado em relação ao virgem. Fato análogo ocorreu no alongamento na ruptura, que reduziu à metade o percentual de distensão antes da quebra. 
Sabe-se que a reciclagem deste material UHMWPE foi realizada pelo método de fundição, ou seja, o material é moído, depois prensado para se obter as placas e por usinagem os corpos-de-prova foram retirados. Portanto, não ocorre uma fusão inter-molecular robusta, motivo pelo qual existe esta perda nas propriedades de tração.

As alterações observadas na densidade, na dureza e abrasão não são significativas, mas no módulo secante existe um ligeiro aumento do reciclado em comparação ao virgem.

Quanto à resistência ao impacto, a perda de quase $42 \%$ deve-se a baixa resistência entre os minúsculos grãos fundidos em relação ao material virgem, isto é, a granulometria de um material moído mecanicamente é irregular, tem grãos de tamanhos variados mesmo depois de micronizados, portanto o contato superficial entre estas partículas também é irregular. Ao passo que no material virgem o "pó" polimerizado tem uma granulometria mais uniforme e regular.

Como já foi dito anteriormente os materiais UHMWPE UTEC 3041 e UHMWPE UTEC 6541 são diferentes na sua formulação, nas suas aplicações e em suas propriedades ${ }^{41}$, portanto seria interessante comparar as propriedades deste material UTEC 6541 virgem com as do UTEC 3041 reciclado.

\section{3) UHMWPE UTEC 3041 reciclado x UHMWPE UTEC 6541 virgem}

$\mathrm{Na}$ Tabela 7 são apresentados os resultados das propriedades do UHMWPE UTEC 3041 reciclado e do UHMWPE UTEC 6541 virgem.

TABELA 7 - Resultados das propriedades do UHMWPE UTEC 3041 reciclado e do UHMWPE UTEC 6541 virgem

\begin{tabular}{|c|c|c|}
\hline Propriedades & UTEC 3041 reciclado & UTEC 6541 virgem \\
\hline Tensão na ruptura (MPa) & 20,8 & 28,5 \\
\hline Alongamento na ruptura (\%) & 121,8 & 200,0 \\
\hline Densidade por empuxo $\left(\mathrm{g} / \mathrm{cm}^{3}\right)$ & $\mathbf{0 , 9 3 3}$ & 0,929 \\
\hline Dureza (Shore D) & 65 & 65 \\
\hline Impacto Charpy $23^{\circ} \mathrm{C}\left(\mathrm{KJ} / \mathrm{m}^{2}\right)$ & 107,8 & $\mathbf{8 4 , 9}$ \\
\hline Módulo Secante à $1 \%$ (MPa) & 709,9 & 699,7 \\
\hline Índice de Abrasão & 24 & 21 \\
\hline
\end{tabular}


Neste caso observou-se que o valor para o impacto do material reciclado é maior, bem como a densidade e o módulo secante, em relação ao material UTEC 6541 virgem.

As propriedades mecânicas de tensão na ruptura e alongamento na ruptura são menores no material reciclado, mas a dureza do material é igual em ambos os casos. Assim sendo, quando a propriedade de impacto for importante pode-se utilizar o UTEC 3041 reciclado, desde que a aplicação do material não seja para fins mais nobres, mesmo porque o índice de abrasão é menor no UTEC 3041 reciclado do que no UTEC 6541 virgem.

4) UHMWPE UTEC 3041 reciclado x UHMWPE UTEC 3041 reciclado IR

4.1 - UHMWPE UTEC 3041 reciclado x UHMWPE UTEC 3041 reciclado IR (100 kGy)

Na Tabela 8 são apresentados os resultados das propriedades do UHMWPE UTEC 3041 reciclado e do UHMWPE UTEC 3041 reciclado IR (100 kGy).

TABELA 8 - Resultados das propriedades do UHMWPE UTEC 3041 reciclado e do UHMWPE UTEC 3041 reciclado IR (100 kGy)

\begin{tabular}{|c|c|c|}
\hline Propriedades & UTEC 3041 reciclado & $\begin{array}{c}\text { UTEC } 3041 \text { reciclado } \\
\text { IR } \\
100 \mathrm{kGy}\end{array}$ \\
\hline Tensão na ruptura (MPa) & 20,8 & 19,2 \\
\hline Alongamento na ruptura (\%) & 121,8 & 51,8 \\
\hline Densidade por empuxo $\left(\mathrm{g} / \mathrm{cm}^{3}\right)$ & 0,933 & 0,940 \\
\hline Dureza (Shore D) & 65 & 65 \\
\hline Impacto Charpy $23^{\circ} \mathrm{C}\left(\mathrm{KJ} / \mathrm{m}^{2}\right)$ & 107,8 & $\mathbf{4 4 , 4}$ \\
\hline Módulo Secante à $1 \%$ (MPa) & 709,9 & 821,7 \\
\hline Índice de Abrasão & 24 & 56 \\
\hline
\end{tabular}

4.2 - UHMWPE UTEC 3041 reciclado x UHMWPE UTEC 3041 reciclado IR (300 kGy)

Na Tabela 9 são apresentados os resultados das propriedades do UHMWPE UTEC 3041 reciclado e do UHMWPE UTEC 3041 reciclado IR (300 kGy). 
TABELA 9 - Resultados das propriedades do UHMWPE UTEC 3041 reciclado e do UHMWPE UTEC 3041 reciclado IR (300 kGy)

\begin{tabular}{|c|c|c|}
\hline Propriedades & UTEC 3041 reciclado & $\begin{array}{c}\text { UTEC } 3041 \text { reciclado } \\
\text { IR } \\
300 \mathrm{kGy}\end{array}$ \\
\hline Tensão na ruptura (MPa) & 20,8 & 18,4 \\
\hline Alongamento na ruptura (\%) & 121,8 & 16,4 \\
\hline Densidade por empuxo $\left(\mathrm{g} / \mathrm{cm}^{3}\right)$ & $\mathbf{0 , 9 3 3}$ & 0,942 \\
\hline Dureza (Shore D) & 65 & 68 \\
\hline Impacto Charpy $23^{\circ} \mathrm{C}\left(\mathrm{KJ} / \mathrm{m}^{2}\right)$ & 107,8 & 22,4 \\
\hline Módulo Secante à 1\% (MPa) & 709,9 & 857,1 \\
\hline Índice de Abrasão & 24 & 100 \\
\hline
\end{tabular}

4.3 - UHMWPE UTEC 3041 reciclado x UHMWPE UTEC 3041 reciclado IR (500 kGy)

Na Tabela 10 são apresentados os resultados das propriedades do UHMWPE UTEC 3041 reciclado e do UHMWPE UTEC 3041 reciclado IR (500 kGy).

TABELA 10 - Resultados das propriedades do UHMWPE UTEC 3041 reciclado e do UHMWPE UTEC 3041 reciclado IR (500 kGy)

\begin{tabular}{|c|c|c|}
\hline Propriedades & UTEC 3041 reciclado & $\begin{array}{c}\text { UTEC } 3041 \text { reciclado } \\
\text { IR } \\
500 \mathrm{kGy}\end{array}$ \\
\hline Tensão na ruptura (MPa) & 20,8 & 17,6 \\
\hline Alongamento na ruptura (\%) & 121,8 & 12,6 \\
\hline Densidade por empuxo $\left(\mathrm{g} / \mathrm{cm}^{3}\right)$ & 0,933 & 0,944 \\
\hline Dureza (Shore D) & 65 & 69 \\
\hline Impacto Charpy $23^{\circ} \mathrm{C}\left(\mathrm{KJ} / \mathrm{m}^{2}\right)$ & 107,8 & 13,9 \\
\hline Módulo Secante à $1 \%$ (MPa) & 709,9 & 891,8 \\
\hline Índice de Abrasão & 24 & 120 \\
\hline
\end{tabular}

Esta é a análise mais importante deste estudo para saber se de posse do UHMWPE reciclado vale a pena irradiá-lo ou não.

Tensão na ruptura $(\mathrm{MPa})$ :

Em todas as doses de radiação estudadas ocorre uma perda nesta propriedade, ou seja o material irradiado fica menos resistente à ruptura quando tracionado. 


\section{Alongamento na ruptura (\%):}

Devido a cisão das moléculas de UHMWPE reciclado após a irradiação, pode-se dizer que o UHMWPE irradiado fica menos dúctil, diminuindo o alongamento.

\section{Densidade por empuxo $\left(\mathrm{g} / \mathrm{cm}^{3}\right)$ :}

A densidade aumenta proporcionalmente com o aumento da dose de radiação: com 100 $\mathrm{kGy}-0,940 \mathrm{~g} / \mathrm{cm}^{3}$, com $300 \mathrm{kGy}-0,942 \mathrm{~g} / \mathrm{cm}^{3}$ e com $500 \mathrm{kGy}-0,944 \mathrm{~g} / \mathrm{cm}^{3}$. Sem irradiação a densidade chega a $0,933 \mathrm{~g} / \mathrm{cm}^{3}$.

Com o aumento da densidade melhora-se a resistência à carga e a deflexão do material.

\section{Dureza (Shore D):}

Os ganhos na dureza são evidentes e importantes, pois 4 pontos na dureza superficial é algo significativo. As amostras recicladas irradiadas apresentaram este comportamento em relação à não irradiada.

\section{Impacto Charpy $23^{\circ} \mathrm{C}\left(\mathrm{KJ} / \mathrm{m}^{2}\right)$ :}

Devido a cisão das moléculas do UHMWPE reciclado, quando irradiado o material fica mais "vítreo" e como se sabe perde também sua tenacidade, portanto a resistência ao impacto é a propriedade mais comprometida quando se irradia uma amostra de UHMWPE reciclada.

\section{Módulo Secante à 1\% (MPa):}

Contrariamente à resistência ao impacto, os ganhos nesta propriedade são expressivos. A resistência à carga é uma característica de destaque neste ensaio.

\section{Índice de Abrasão:}

A perda no índice de abrasão é acentuada à proporção que se aumentou a dose de radiação. Portanto fica claro que, o material reciclado quanto mais submetido à irradiação, pior é sua resistência a abrasão.

Portanto, se necessitar de alta resistência ao impacto não se deve irradiar o UHMWPE reciclado, mas se necessitar melhorar os valores de carga e deformação, sim. 
5) UHMWPE UTEC 3041 reciclado IR x UHMWPE UTEC 3041 virgem

5.1 - UHMWPE UTEC 3041 reciclado IR (100 kGy) x UHMWPE UTEC 3041 virgem

Na Tabela 11 são apresentados os resultados das propriedades do UHMWPE UTEC 3041 reciclado irradiado (100 kGy) e do UHMWPE UTEC 3041 virgem.

TABELA 11 - Resultados das propriedades do UHMWPE UTEC 3041 reciclado IR (100 kGy) e do UHMWPE UTEC 3041 virgem

\begin{tabular}{ccc}
\hline Propriedades & $\begin{array}{c}\text { UTEC 3041 reciclado } \\
\text { IR } \\
100 \mathrm{kGy}\end{array}$ & $\begin{array}{c}\text { UTEC 3041 } \\
\text { virgem }\end{array}$ \\
\hline Tensão na ruptura $(\mathrm{MPa})$ & 19,2 & \\
Alongamento na ruptura $(\%)$ & 51,8 & 28,4 \\
Densidade por empuxo $\left(\mathrm{g} / \mathrm{cm}^{3}\right)$ & 0,940 & $\mathbf{2 4 8 , 0}$ \\
Dureza $($ Shore $\mathrm{D})$ & $\mathbf{6 5}$ & $\mathbf{0 , 9 3 0}$ \\
Impacto Charpy $23^{\circ} \mathrm{C}\left(\mathrm{KJ} / \mathrm{m}^{2}\right)$ & 44,4 & 64 \\
Módulo Secante à $1 \%(\mathrm{MPa})$ & $\mathbf{8 2 1 , 7}$ & $\mathbf{1 8 5 , 3}$ \\
Índice de Abrasão & 56 & 703,9 \\
\hline
\end{tabular}

5.2 - UHMWPE UTEC 3041 reciclado IR (300 kGy) x UHMWPE UTEC 3041 virgem

Na Tabela 12 são apresentados os resultados das propriedades do UHMWPE UTEC 3041 reciclado irradiado (300 kGy) e do UHMWPE UTEC 3041 virgem.

TABELA 12 - Resultados das propriedades do UHMWPE UTEC 3041 reciclado IR (300 kGy) e do UHMWPE UTEC 3041 virgem

\begin{tabular}{|c|c|c|}
\hline Propriedades & $\begin{array}{c}\text { UTEC } 3041 \text { reciclado } \\
\text { IR } \\
300 \mathrm{kGy}\end{array}$ & $\begin{array}{c}\text { UTEC 3041 } \\
\text { virgem }\end{array}$ \\
\hline Tensão na ruptura (MPa) & 18,4 & 28,4 \\
\hline Alongamento na ruptura (\%) & 16,4 & 248,0 \\
\hline Densidade por empuxo $\left(\mathrm{g} / \mathrm{cm}^{3}\right)$ & 0,942 & $\mathbf{0 , 9 3 0}$ \\
\hline Dureza (Shore D) & 68 & 64 \\
\hline Impacto Charpy $23^{\circ} \mathrm{C}\left(\mathrm{KJ} / \mathrm{m}^{2}\right)$ & 22,4 & 185,3 \\
\hline Módulo Secante à $1 \%$ (MPa) & 857,1 & 703,9 \\
\hline Índice de Abrasão & 100 & 25 \\
\hline
\end{tabular}


5.3 - UHMWPE UTEC 3041 reciclado IR (500 kGy) x UHMWPE UTEC 3041 virgem

$\mathrm{Na}$ Tabela 13 são apresentados os resultados das propriedades do UHMWPE UTEC 3041 reciclado irradiado (500 kGy) e do UHMWPE UTEC 3041 virgem.

TABELA 13 - Resultados das propriedades do UHMWPE UTEC 3041 reciclado IR (500 kGy) e do UHMWPE UTEC 3041 virgem

\begin{tabular}{ccc}
\hline Propriedades & UTEC 3041 reciclado & UTEC 3041 \\
& IR & Virgem \\
& $500 \mathrm{kGy}$ & \\
\hline Tensão na ruptura $(\mathrm{MPa})$ & 17,6 & $\mathbf{2 8 , 4}$ \\
Alongamento na ruptura $(\%)$ & 12,6 & $\mathbf{2 4 8 , 0}$ \\
Densidade por empuxo $\left(\mathrm{g} / \mathrm{cm}^{3}\right)$ & $\mathbf{0 , 9 4 4}$ & $\mathbf{0 , 9 3 0}$ \\
Dureza $($ Shore $\mathrm{D})$ & $\mathbf{6 9}$ & $\mathbf{6 4}$ \\
Impacto Charpy $23^{\circ} \mathrm{C}\left(\mathrm{KJ} / \mathrm{m}^{2}\right)$ & 13,9 & 185,3 \\
Módulo Secante à $1 \%(\mathrm{MPa})$ & $\mathbf{8 9 1 , 8}$ & $\mathbf{7 0 3 , 9}$ \\
Índice de Abrasão & $\mathbf{1 2 0}$ & $\mathbf{2 5}$ \\
\hline
\end{tabular}

Observa-se nas Tabelas 11, 12 e 13 que ocorre um decréscimo acentuado na tensão na ruptura e no alongamento, à proporção que se aumenta a dose de radiação no UHMWPE UTEC 3041 reciclado em comparação com os dados obtidos com o material virgem.

$\mathrm{Na}$ resistência ao impacto, igualmente observam-se perdas nesta propriedade quando o material foi submetido a valores mais altos de dose de radiação.

A medida que a dose de radiação aumenta observa-se um aumento no valor da dureza e na densidade. Também se observa um aumento significativo no módulo secante do UHMWPE UTEC 3041 reciclado irradiado a medida que a dose de radiação aumenta, e o efeito inverso ocorre no índice de abrasão que piora com a radiação.

Portanto, para obtenção de um UHMWPE com melhores propriedades de dureza por penetração e módulo secante maior, deve-se irradiá-lo a 500 kGy. 
6) UHMWPE UTEC 3041 reciclado IR x UHMWPE UTEC 6541 virgem

6.1 - UHMWPE UTEC 3041 reciclado IR (100 kGy) x UHMWPE UTEC 6541 virgem

Na Tabela 14 são apresentados os resultados das propriedades do UHMWPE UTEC 3041 reciclado irradiado (100 kGy) e do UHMWPE UTEC 6541 virgem.

TABELA 14 - Resultados das propriedades do UHMWPE UTEC 3041 reciclado IR (100 kGy) e do UHMWPE UTEC 6541 virgem

\begin{tabular}{ccc}
\hline Propriedades & UTEC 3041 reciclado & UTEC 6541 \\
& IR & Virgem \\
& $100 \mathrm{kGy}$ & \\
\hline Tensão na ruptura $(\mathrm{MPa})$ & 19,2 & 28,5 \\
Alongamento na ruptura $(\%)$ & 51,8 & 200,0 \\
Densidade por empuxo $\left(\mathrm{g} / \mathrm{cm}^{3}\right)$ & 0,940 & 0,929 \\
Dureza $($ Shore $\mathrm{D})$ & $\mathbf{6 5}$ & $\mathbf{6 5}$ \\
Impacto Charpy $23^{\circ} \mathrm{C}\left(\mathrm{KJ} / \mathrm{m}^{2}\right)$ & 44,4 & $\mathbf{8 4 , 9}$ \\
Módulo Secante à $1 \%(\mathrm{MPa})$ & $\mathbf{8 2 1 , 7}$ & $\mathbf{6 9 9 , 7}$ \\
Índice de Abrasão & 56 & 21 \\
\hline
\end{tabular}

6.2 - UHMWPE UTEC 3041 reciclado IR (300 kGy) x UHMWPE UTEC 6541 virgem

Na Tabela 15 são apresentados os resultados das propriedades do UHMWPE UTEC 3041 reciclado irradiado (300 kGy) e do UHMWPE UTEC 6541 virgem.

TABELA 15 - Resultados das propriedades do UHMWPE UTEC 3041 reciclado IR (300 kGy) e do UHMWPE UTEC 6541 virgem

\begin{tabular}{ccc}
\hline Propriedades & UTEC 3041 reciclado & UTEC 6541 \\
& IR & Virgem \\
& $300 \mathrm{kGy}$ & \\
\hline Tensão na ruptura $(\mathrm{MPa})$ & $\mathbf{1 8 , 4}$ & $\mathbf{2 8 , 5}$ \\
Alongamento na ruptura $(\%)$ & 16,4 & $\mathbf{2 0 0 , 0}$ \\
Densidade por empuxo $\left(\mathrm{g} / \mathrm{cm}^{3}\right)$ & $\mathbf{0 , 9 4 2}$ & $\mathbf{0 , 9 2 9}$ \\
Dureza $($ Shore $\mathrm{D})$ & $\mathbf{6 8}$ & $\mathbf{6 5}$ \\
Impacto Charpy $23^{\circ} \mathrm{C}\left(\mathrm{KJ} / \mathrm{m}^{2}\right)$ & $\mathbf{2 2 , 4}$ & $\mathbf{8 4 , 9}$ \\
Módulo Secante à $1 \%(\mathrm{MPa})$ & $\mathbf{8 5 7 , 1}$ & $\mathbf{6 9 9 , 7}$ \\
Índice de Abrasão & 100 & $\mathbf{2 1}$ \\
\hline
\end{tabular}


Na Tabela 16 são apresentados os resultados das propriedades do UHMWPE UTEC 3041 reciclado irradiado (500 kGy) e do UHMWPE UTEC 6541 virgem.

TABELA 16 - Resultados das propriedades do UHMWPE UTEC 3041 reciclado IR (500 kGy) e do UHMWPE UTEC 6541 virgem

\begin{tabular}{ccc}
\hline Propriedades & UTEC 3041 reciclado & UTEC 6541 \\
& IR & Virgem \\
& $500 \mathrm{kGy}$ & \\
\hline Tensão na ruptura $(\mathrm{MPa})$ & 17,6 & 28,5 \\
Alongamento na ruptura $(\%)$ & 12,6 & 200,0 \\
Densidade por empuxo $\left(\mathrm{g} / \mathrm{cm}^{3}\right)$ & 0,944 & 0,929 \\
Dureza $($ Shore $\mathrm{D})$ & 69 & 65 \\
Impacto Charpy $23^{\circ} \mathrm{C}\left(\mathrm{KJ} / \mathrm{m}^{2}\right)$ & 13,9 & $\mathbf{8 4 , 9}$ \\
Módulo Secante à $1 \%(\mathrm{MPa})$ & $\mathbf{8 9 1 , 8}$ & $\mathbf{6 9 9 , 7}$ \\
Índice de Abrasão & 120 & 21 \\
\hline
\end{tabular}

Nas Tabelas 14, 15 e 16 observa-se as diferenças entre o UHMWPE UTEC 3041 reciclado irradiado a 100, 300 e 500 kGy e o UHMWPE UTEC 6541 virgem.

Basicamente o módulo secante é a alteração mais significativa e é crescente à proporção que se aumenta a dose de radiação. O módulo secante mede o módulo elástico na tração, ou seja, a resistência a carga que o material suporta, sua rigidez quando submetido a esforço e sua deformação elástica antes de atingir a zona plástica (deformação permanente).

Outra característica importante é a resistência a abrasão que diminui à proporção que se aumentam as doses de radiação.

Observa-se a alta resistência a deformação no UHMWPE UTEC 3041 reciclado IR a 500 kGy em relação ao UHMWPE UTEC 6541 virgem num percentual superior a $27 \%$.

Portanto, para obtenção de um material para aplicação com alta resistência a deformação recomenda-se a irradiação do UHMWPE reciclado. 
7) UHMWPE UTEC 3041 reciclado IR x UHMWPE UTEC 3041 virgem IR

7.1 - UHMWPE UTEC 3041 reciclado IR (100 kGy) x UHMWPE UTEC 3041 virgem IR (100 kGy)

Na Tabela 17 são apresentados os resultados das propriedades do UHMWPE UTEC 3041 reciclado irradiado (100 kGy) e do UHMWPE UTEC 3041 virgem IR (100 kGy).

TABELA 17 - Resultados das propriedades do UHMWPE UTEC 3041 reciclado IR (100 kGy) e do UHMWPE UTEC 3041 virgem IR (100 kGy)

\begin{tabular}{|c|c|c|}
\hline Propriedades & $\begin{array}{c}\text { UTEC } 3041 \text { reciclado } \\
\text { IR } \\
100 \mathrm{kGy}\end{array}$ & $\begin{array}{c}\text { UTEC 3041 } \\
\text { virgem IR } \\
100 \mathrm{kGy}\end{array}$ \\
\hline Tensão na ruptura (MPa) & 19,2 & 23,05 \\
\hline Alongamento na ruptura (\%) & 51,8 & 95,7 \\
\hline Densidade por empuxo $\left(\mathrm{g} / \mathrm{cm}^{3}\right)$ & 0,940 & 0,938 \\
\hline Dureza (Shore D) & 65 & 66 \\
\hline Impacto Charpy $23^{\circ} \mathrm{C}\left(\mathrm{KJ} / \mathrm{m}^{2}\right)$ & $\mathbf{4 4 , 4}$ & 57,4 \\
\hline Módulo Secante à $1 \%$ (MPa) & 821,7 & 810,6 \\
\hline Índice de Abrasão & 56 & 46 \\
\hline
\end{tabular}

7.2 - UHMWPE UTEC 3041 reciclado IR (300 kGy) x UHMWPE UTEC 3041 virgem IR (300 kGy)

Na Tabela 18 são apresentados os resultados das propriedades do UHMWPE UTEC 3041 reciclado irradiado (300 kGy) e do UHMWPE UTEC 3041 virgem IR (300 kGy).

TABELA 18 - Resultados das propriedades do UHMWPE UTEC 3041 reciclado IR (300 kGy) e do UHMWPE UTEC 3041 virgem IR (300 kGy)

\begin{tabular}{ccc}
\hline Propriedades & UTEC 3041 reciclado & UTEC 3041 \\
& IR & virgem IR \\
& $300 \mathrm{kGy}$ & $300 \mathrm{kGy}$ \\
\hline Tensão na ruptura $(\mathrm{MPa})$ & $\mathbf{1 8 , 4}$ & $\mathbf{2 1 , 4}$ \\
Alongamento na ruptura $(\%)$ & 16,4 & $\mathbf{5 0 , 9}$ \\
Densidade por empuxo $\left(\mathrm{g} / \mathrm{cm}^{3}\right)$ & $\mathbf{0 , 9 4 2}$ & $\mathbf{0 , 9 3 9}$ \\
Dureza $($ Shore $\mathrm{D})$ & $\mathbf{6 8}$ & $\mathbf{6 7}$ \\
Impacto Charpy $23^{\circ} \mathrm{C}\left(\mathrm{KJ} / \mathrm{m}^{2}\right)$ & $\mathbf{2 2 , 4}$ & $\mathbf{2 2 , 0}$ \\
Módulo Secante à $1 \%(\mathrm{MPa})$ & $\mathbf{8 5 7 , 1}$ & $\mathbf{8 4 7 , 9}$ \\
Índice de Abrasão & 100 & $\mathbf{9 3}$ \\
\hline
\end{tabular}


7.3 - UHMWPE UTEC 3041 reciclado IR (500 kGy) x UHMWPE UTEC 3041 virgem IR (500 kGy)

Na Tabela 19 são apresentados os resultados das propriedades do UHMWPE UTEC 3041 reciclado irradiado (500 kGy) e do UHMWPE UTEC 3041 virgem IR (500 kGy).

TABELA 19 - Resultados das propriedades do UHMWPE UTEC 3041 reciclado IR (500 kGy) e do UHMWPE UTEC 3041 virgem IR (500 kGy)

\begin{tabular}{|c|c|c|}
\hline Propriedades & $\begin{array}{c}\text { UTEC } 3041 \text { reciclado } \\
\text { IR } \\
500 \mathrm{kGy}\end{array}$ & $\begin{array}{c}\text { UTEC 3041 } \\
\text { virgem IR } \\
500 \mathrm{kGy}\end{array}$ \\
\hline Tensão na ruptura (MPa) & 17,6 & 21,3 \\
\hline Alongamento na ruptura (\%) & 12,6 & 30,4 \\
\hline Densidade por empuxo $\left(\mathrm{g} / \mathrm{cm}^{3}\right)$ & 0,944 & 0,941 \\
\hline Dureza (Shore D) & 69 & 68 \\
\hline Impacto Charpy $23^{\circ} \mathrm{C}\left(\mathrm{KJ} / \mathrm{m}^{2}\right)$ & 13,9 & 17,3 \\
\hline Módulo Secante à 1\% (MPa) & 891,8 & 888,4 \\
\hline Índice de Abrasão & 120 & 140 \\
\hline
\end{tabular}

A comparação entre os resultados das amostras de UHMWPE UTEC 3041 reciclado e UHMWPE UTEC 3041 virgem, ambos irradiados, mostra alguns pontos relevantes. Em todas as amostras analisadas (Tabelas 17, 18 e 19), observa-se uma perda nas propriedades do UTEC 3041 reciclado irradiado em relação ao UTEC 3041 virgem irradiado em todas as doses de radiação, à exceção da densidade e dureza que permanecem praticamente iguais. Na resistência ao impacto na dose de 300 kGy existe uma igualdade nos valores obtidos, em torno de $22 \mathrm{KJ} / \mathrm{m}^{2}$.

O índice de abrasão também piora muito em ambos os casos à medida que se aumenta a dose de radiação. 
8) UHMWPE UTEC 3041 reciclado IR x UHMWPE UTEC 6541 virgem IR

8.1 - UHMWPE UTEC 3041 reciclado IR (100 kGy) x UHMWPE UTEC 6541 virgem IR (100 kGy)

Na Tabela 20 são apresentados os resultados das propriedades do UHMWPE UTEC 3041 reciclado irradiado (100 kGy) e do UHMWPE UTEC 6541 virgem IR (100 kGy).

TABELA 20 - Resultados das propriedades do UHMWPE UTEC 3041 reciclado IR (100 kGy) e do UHMWPE UTEC 6541 virgem IR (100 kGy)

\begin{tabular}{ccc}
\hline Propriedades & UTEC 3041 reciclado & UTEC 6541 \\
& IR & virgem IR \\
& $100 \mathrm{kGy}$ & $100 \mathrm{kGy}$ \\
\hline Tensão na ruptura $(\mathrm{MPa})$ & 19,2 & $\mathbf{2 8 , 2}$ \\
Alongamento na ruptura $(\%)$ & 51,8 & 111,2 \\
Densidade por empuxo $\left(\mathrm{g} / \mathrm{cm}^{3}\right)$ & $\mathbf{0 , 9 4 0}$ & $\mathbf{0 , 9 3 8}$ \\
Dureza $\left(\right.$ Shore $\left.^{\mathrm{D}}\right)$ & $\mathbf{6 5}$ & $\mathbf{6 7}$ \\
Impacto Charpy $23^{\circ} \mathrm{C}\left(\mathrm{KJ} / \mathrm{m}^{2}\right)$ & 44,4 & $\mathbf{6 3 , 5}$ \\
Módulo Secante à $1 \%(\mathrm{MPa})$ & $\mathbf{8 2 1 , 7}$ & $\mathbf{8 2 0 , 6}$ \\
Índice de Abrasão & $\mathbf{5 6}$ & $\mathbf{5 1}$ \\
\hline
\end{tabular}

8.2 - UHMWPE UTEC 3041 reciclado IR (300 kGy) x UHMWPE UTEC 6541 virgem IR (300 kGy)

Na Tabela 21 são apresentados os resultados das propriedades do UHMWPE UTEC 3041 reciclado irradiado (300 kGy) e do UHMWPE UTEC 6541 virgem IR (300 kGy).

TABELA 21 - Resultados das propriedades do UHMWPE UTEC 3041 reciclado IR (300 kGy) e do UHMWPE UTEC 6541 virgem IR (300 kGy)

\begin{tabular}{|c|c|c|}
\hline Propriedades & $\begin{array}{c}\text { UTEC } 3041 \text { reciclado } \\
\text { IR } \\
300 \mathrm{kGy}\end{array}$ & $\begin{array}{c}\text { UTEC 6541 } \\
\text { virgem IR } \\
300 \mathrm{kGy}\end{array}$ \\
\hline Tensão na ruptura (MPa) & 18,4 & 22,9 \\
\hline Alongamento na ruptura (\%) & 16,4 & $\mathbf{5 5 , 9}$ \\
\hline Densidade por empuxo $\left(\mathrm{g} / \mathrm{cm}^{3}\right)$ & 0,942 & 0,940 \\
\hline Dureza (Shore D) & 68 & 68 \\
\hline Impacto Charpy $23^{\circ} \mathrm{C}\left(\mathrm{KJ} / \mathrm{m}^{2}\right)$ & 22,4 & 33,0 \\
\hline Módulo Secante à 1\% (MPa) & 857,1 & 834,8 \\
\hline Índice de Abrasão & 100 & 84 \\
\hline
\end{tabular}


8.3 - UHMWPE UTEC 3041 reciclado IR (500 kGy) x UHMWPE UTEC 6541 virgem IR (500 kGy)

Na Tabela 22 são apresentados os resultados das propriedades do UHMWPE UTEC 3041 reciclado irradiado (500 kGy) e do UHMWPE UTEC 6541 virgem IR (500 kGy).

TABELA 22 - Resultados das propriedades do UHMWPE UTEC 3041 reciclado IR (500 kGy) e do UHMWPE UTEC 6541 virgem IR (500 kGy)

\begin{tabular}{ccc}
\hline Propriedades & UTEC 3041 reciclado & UTEC 6541 \\
& IR & virgem IR \\
& $500 \mathrm{kGy}$ & $500 \mathrm{kGy}$ \\
\hline Tensão na ruptura $(\mathrm{MPa})$ & 17,6 & 21,9 \\
Alongamento na ruptura $(\%)$ & 12,6 & 32,7 \\
Densidade por empuxo $\left(\mathrm{g} / \mathrm{cm}^{3}\right)$ & 0,944 & 0,942 \\
Dureza $($ Shore $\mathrm{D})$ & 69 & 69 \\
Impacto Charpy $23^{\circ} \mathrm{C}\left(\mathrm{KJ} / \mathrm{m}^{2}\right)$ & 13,9 & 23,7 \\
Módulo Secante à $1 \%(\mathrm{MPa})$ & $\mathbf{8 9 1 , 8}$ & $\mathbf{8 5 1 , 9}$ \\
Índice de Abrasão & 120 & 105 \\
\hline
\end{tabular}

Nesta comparação observa-se apenas a predominância do módulo secante no UHMWPE UTEC 3041 reciclado irradiado em todas as doses de radiação aplicadas. Nas demais comparações é notória a predominância das propriedades do UHMWPE UTEC 6541 virgem irradiado sobre o UTEC 3041 reciclado irradiado, à exceção da dureza e densidade que se equivalem.

Observa-se ainda, que o índice de abrasão é menor no UTEC 3041 reciclado irradiado do que no UTEC 6541 virgem, também irradiado. 


\section{2 - Calorimetria Exploratória Diferencial (DSC)}

Na Tabela 23 são apresentados os resultados de DSC.

TABELA 23 - Resultados de DSC das amostras de UHMWPE UTEC 3041 virgem e reciclado e de UHMWPE UTEC 6541 virgem, não irradiado e irradiado a diferentes doses

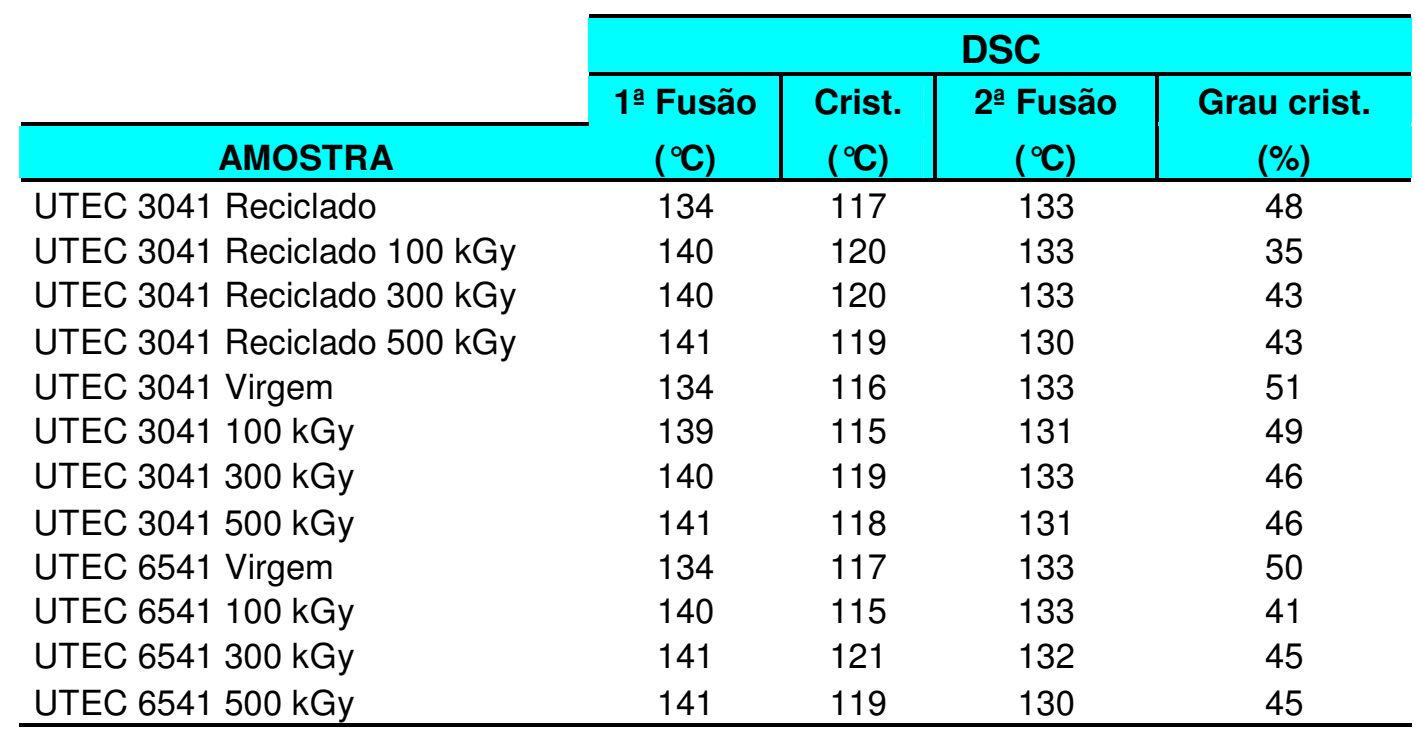

$\mathrm{Na}$ análise térmica (DSC) tem-se duas fusões: na primeira fusão tem-se o histórico térmico típico do material e na segunda se estabelece a padronização do material. Portanto, para efeitos comparativos toma-se por base a segunda fusão.

Por meio desta técnica pode-se estudar as transições térmicas de interesse, como por exemplo, temperatura de fusão e determinação da porcentagem de cristalinidade.

No UHMWPE onde o processo de transformação é geralmente o de compressão, o DSC é utilizado para determinar a energia de fusão necessária para transformar o pó de UHMWPE em chapa.

Quanto à porcentagem de cristalinidade, os polímeros que se apresentam em cadeias distribuídas em regiões amorfas e cristalinas organizadas entre si são denominados de materiais semicristalinos. A relação entre região amorfa e cristalina de uma amostra de 
polímero é expressa em porcentagem de cristalinidade ou grau de cristalinidade. A variação na porcentagem de cristalinidade pode afetar as diversas propriedades do material.

Nos três grupos de amostras:

1) UTEC 3041 reciclado sem irradiação e com doses de 100, 300 e 500 kGy.

2) UTEC 3041 virgem sem irradiação e com doses de 100, 300 e 500 kGy.

3) UTEC 6541 virgem sem irradiação e com doses de 100, 300 e 500 kGy.

Observa-se que as temperaturas de fusão não variaram até $300 \mathrm{kGy}$, contudo ao aplicar-se $500 \mathrm{kGy}$ notou-se uma queda de $3^{\circ} \mathrm{C}$, de 133 para $130^{\circ} \mathrm{C}$, no primeiro e terceiro grupo, e de $133^{\circ} \mathrm{C}$ para $131^{\circ} \mathrm{C}$ no segundo grupo (UTEC 3041 virgem).

Já no grau de cristalinidade ao aplicar a radiação observou-se uma queda neste valor em função da formação de reticulação, portanto desordenando o polímero.

\section{3 - Efeito na coloração do UHMWPE, devido a radiação}

Na Figura 8 é mostrada a mudança de cor das amostras de UHMWPE UTEC 3041 em função da dose de radiação. Neste caso observa-se o escurecimento dos corpos-de-prova do UHMWPE UTEC 3041 quando submetido a diferentes doses de radiação. Este escurecimento nas amostras deve-se, principalmente, a oxidação do UHMWPE durante a irradiação devido ao fato que as irradiações foram realizadas em presença de oxigênio, indicando que houve degradação do polímero quando submetido a radiação. Este comportamento foi observado tanto nas amostras do UHMWPE virgem como reciclado. 


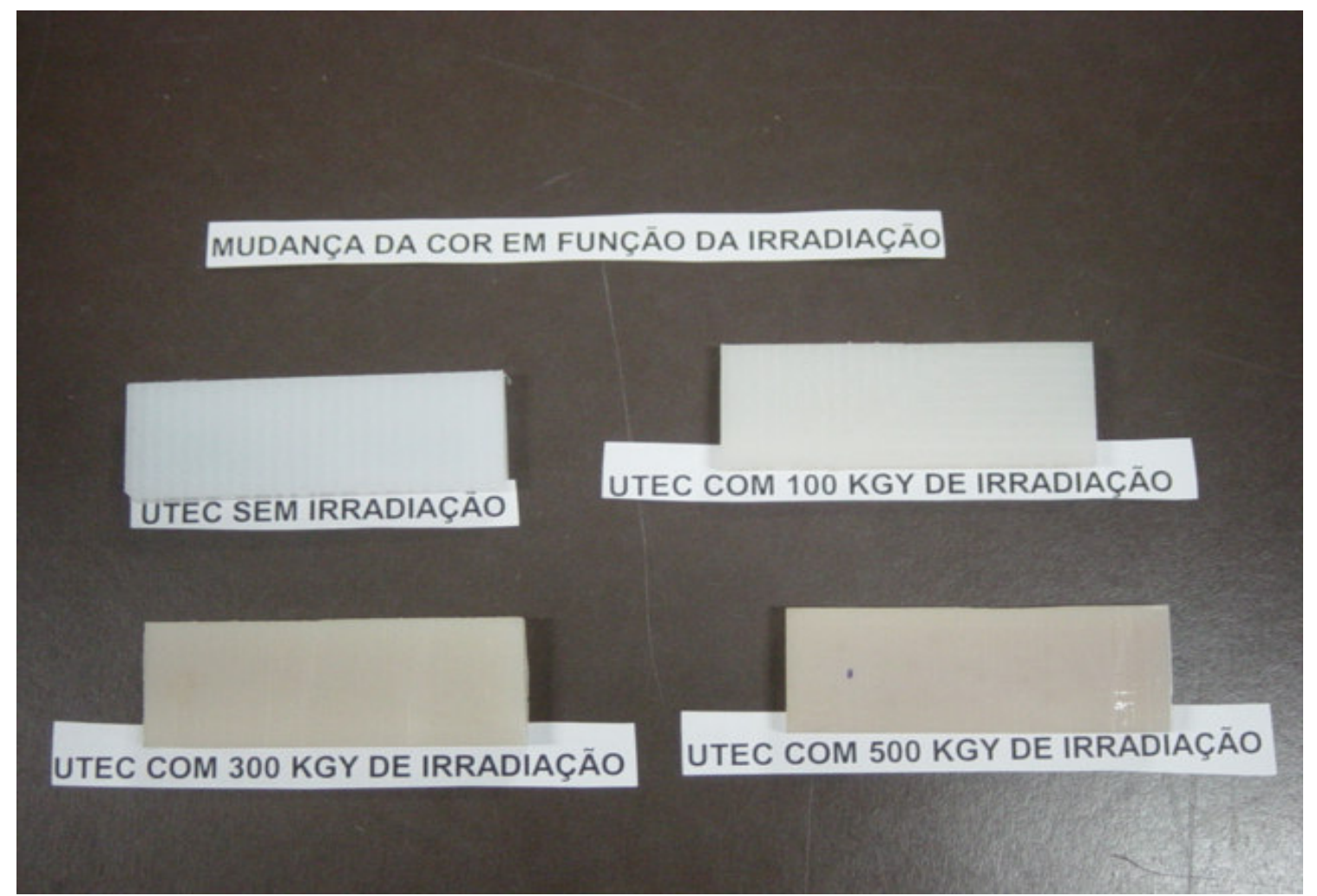

FIGURA 8 - Mudança de cor das amostras de UHMWPE UTEC 3041 em função da dose de radiação 


\section{7 - CONCLUSÕES}

As propriedades do UHMWPE são fatores importantes para serem confrontados com as funções que ele vai exercer no produto final e com o processo de industrialização pelo qual ele vai passar até sua forma final.

O UHMWPE UTEC 3041 virgem possui uma resistência ao impacto maior que o UHMWPE UTEC 6541 virgem, portanto ele seria ideal para uma utilização onde uma alta resistência ao impacto fosse requerida.

O UHMWPE UTEC 3041 reciclado apresentou um valor de impacto maior que o UHMWPE UTEC 6541 virgem.

Com o aumento da dose de radiação observou-se que a cadeia polimérica de todos os tipos de UHMWPE sofreu modificações em sua estrutura, diminuindo a tensão na ruptura; a dureza do material aumentou e a resistência ao impacto diminuiu, indicando que a rigidez do material aumentou tornando-o mais frágil e a resistência à abrasão do material reciclado diminuiu significativamente. Observou-se, também, um aumento no módulo secante (módulo de elasticidade) dos diferentes tipos de UHMWPE estudados.

Em relação a sua reciclagem, apesar de ser complexa, pois não foi realizada pelos métodos convencionais mais utilizados, pode-se afirmar que é viável.

Os resultados mostraram que com o aumento da dose de radiação as temperaturas de fusão sofreram redução, bem como o grau de cristalinidade.

As mudanças observadas nas propriedades do UHMWPE irradiado, tanto virgem como reciclado, deve-se a degradação do material devido à oxidação que ocorre durante a irradiação com feixe de elétrons. 


\section{REFERÊNCIAS BIBLIOGRÁFICAS}

1. ZAMFIROVA, G.; MISHEVA, M.; BENAVENTE, R.; PÉREZ, E.; PERÑA, J.M. GAMMA. Irradiated Ultra High Molecular Weight Polyethylene. In: 9 Simpósio Latinoamericano de Polímeros, July 2-4, 2004, Valencia, Spain. Proceedings... Valencia:SSMat, 2004. 1 Cd-rom.

2. VASCONCELLOS, L.A.; BLANDO, E.; HUBLER, R. Avaliação da proteção de revestimentos tipo filme fino para UHMWPE exposto a radiação X. In: XVI Congresso Brasileiro de Engenharia e Ciência dos Materiais, Nov. 28-Dec. 2, 2004, Porto Alegre, RS. Proceedings...Porto Alegre:SBPMat, 2004. 1 Cd-rom.

3. ELTOM, A.E.; SOARES, J.C.M; BONELLI, C.M.C.; MANO, E.B. Strutural changes followed g-irradiation of UHMWPE. In: XVI Congresso Brasileiro de Engenharia e Ciência dos Materiais, Nov. 28-Dec. 2, 2004, Porto Alegre, RS. Proceedings...Porto Alegre:SBPMat, 2004. 1 Cd-rom.

4. AYDINLI, BAHATTIN; TINÇER, TEOMAN. Radiation grafting of various watersoluble monomers on ultra-high molecular weight polyethylene powder. Part III: Preparation of compression moulded films, and water-uptake and morphological studies. Rad. Phys. Chem., v.62, p.337-343, 2001.

5. SHEN, F.W.; MCKELLOP, H.A.; SALOVEY, R. Irradiation of chemically crosslinked ultrahigh molecular weight polyethylene. 1995.

6. DJOKOVIC, V.; KOSTOSKI, D.; ANIN, D.; DUDIC, D. Effects of gamma irradiation on the stress relaxation of draw ultrahigh molecular weight polyethylene. Rad. Phys. Chem., v.55, p.605-607, 1999.

7. KANG, P. H.; NHO, Y. C. The effect of y-irradiation on ultra-high molecular weight polyethylene recrystallized under different cooling conditions. Rad. Phys. Chem., v.60, p.79-87, 2001. 
8. BRACCO, P.; BRACH DEL PREVER, E.M.; CANNAS, M.; LUDA, M. P.; COSTA, L. Oxidation behaviour in prosthetic UHMWPE components sterilised with high energy radiation in a low-oxygen environment. Polym. Degrad. Stab., v.91, p.2030-2038, 2006.

9. MEDEL, F. J.; GARCIA-ÁLVAREZ, F.; GOMEZ-BARRENA, E.; PUÉRTOLAS, J. A. Microstructure changes of extruded ultra high molecular weight polyethylene after gamma irradiation and shelf-aging. Polym. Degrad. Stab., v.88, p.435-443, 2005.

10. SUAREZ, JOÃO CARLOS MIGUEZ; BIASI, RONALDO SÉRGIO. Effect of gamma irradiation on the ductile-to-brittle transition in ultra-high molecular weight polyethylene. Polym. Degrad. Stab., v.82, p.221-227, 2003.

11. AL-MA'ADEED, M.A.; AL-QARADAWI, I.Y.; MADI, N.; AL-THANI, N.J. The effect of gamma irradiation and shelf aging in air on the oxidation of ultra-high molecular weight polyethylene. Appl. Surface Sci., p.3316-3322, 2005.

12. BOLETINS TÉCNICOS DA CORMATEC, 2001.

13. BOLETINS TÉCNICOS DA DAY BRASIL, 2002.

14. www.midsa.com.mx / produ_uhmw.php, Acesso em jan. 2006.

15. www.daybrasil.com.br (produtos - UHMW CERAM-P), Acesso em jan. 2006.

16. www.daybrasil.com.br (produtos - UHMW TIVAR), Acesso em jan. 2006.

17. SPIEGELBERG, S. Analytical Techniques for Assessing the Effects of Radiation on UHMWPE. (www.campoly.com), 2001

18. FRANK, M.R.; SMITH, J.J.; BACON R.C. J. Polym. Sci., v.13, p.535-547, 1954.

19. COSTA L.; LUDA, M.P.; TROSSARELLI, L.; BRACH DEL PREVER E.M., CROVA M.; GALLINARO, P. Oxidation in orthopaedic UHMWPE sterilized by gammaradiation and ethylene oxide Biomaterials, v.19, p.659-668, 1998. 
20. PREMNATH, V.; HARRIS, W.H.; JASTY, M.; MERRILL, E.W. Articular implants: an analysis of the oxidation problem gamma sterilization of UHMWPE. Biomaterials, v.17, p.1741-1753, 1996.

21. BELL, C.J.; WALKER, P.S.; ABEYSUNDERA, M.; SIMMONS, J.M.H.; KING, P.M.; BLUNN, G.W. The Journal of Arthroplasty, v.13, p.280-290, 1998.

22. SPIEGELBERG, S.H.; SCHAFFNER, S.R. Oxidation profiles in shelf-stored ultra high molecular weight polyethylene samples, Society for Biomaterials. In: 25th Annual Meeting, Proceedings...Providence, RI, 1999.

23. LYONS, B.J.; JOHNSON, W.C.; REICHMANIS E.; FRANK, C.W.; O'DONNELL, J.H. Irradiation of Polymer Materials: Processes, Mechanisms, and Applications. American Chemical Society, v.527, p.62-73, 1993.

24. JOHNSON, W.C.; LYONS, B.J. Radiolytic formation and decay of trans-vinydene unsaturation in polyethylene: Fourier transform infra-red measurements. Rad. Phys. Chem., v.46, p.829-832, 1995.

25. MURATOGLU, O.K.; BRAGDON, C.R.; O'CONNOR, D.O.; JASTY, M.; HARRIS, W.H.; GUL, R.; McGARRY, F. Unified wear model for highly crosslinked ultra high molecular weight polyethylene (UHMWPE). Biomaterials, v.20, p.1463-1470, 1999.

26. HENDUS H., SCHNELL G., Kunstoffe, v.51, p.69-74, 1961.

27. SOLTI, A.; HUMMEL, D.D.; SIMAK, P. Die Makromol. Chem., In: Macromol. Symp. H. Hocker, v.5, p.105-133, 1986.

28. SANFORD, W.M.; SAUM, K.A. Accelerated oxidative aging testing of UHMWPE, In: Orthopedic Research Society Annual Meeting, 1995, Orlando, FL. Proceedings... Orlando, 1995.

29. SUN, D.C. A simple accelerated aging method for long-term post-radiation effects in UHMWPE implants, In: Fifth World Biomaterials Congress, 1996, Toronto, Proceedings...Toronto, 1996.

30. RAMAMURTI, B.S.; ESTOK, D.M.; JASTY, M.; HARRIS, W.H. J. Bon. Joint Surg., v.16, p.365-369, 1998. 
31. SCHMIDT, M.S.; HAMILTON, J.V.; DEGRENIER, C.; THISELL, J. Comparison of UHMWPE Wear Produced by Pin-on-Flat and Hip Simulator Testing, In: 24th Annual Meeting of the Society for Biomaterials, Proceedings...1998.

32. MCKELLOP, H. J. Biomed. Mat. Res., v.12, p.895, 1978.

33. ARTEL, B.W.H. Efeito da Radiação em Polímeros. Revista Plástico Moderno, Agosto, 2000.

34. YAMASAKI, M.C.R. A cura de tintas, vernizes e revestimentos por ultravioleta e feixe de elétrons. IPEN \& ATBCR, SP, 1997.

35. MORAES, R. A Tolerância dos Polímeros à Radiação. Revista Plástico Moderno, Agosto, 2000.

36. SPINKS, J.W.T. In Introduction to radiation chemistry. 3.ed. New York, N.Y.: John Wiley Sons, Inc., 1990.

37. CLEGG, D.W., COLLYER A.A. Irradiation Effects on Polymers. London, London: Elsevier Applied Science, 1991.

38. BOLT, R.O.; CARROL, J.G. Radiation Effects on Organic Materials. New York, N.Y.: Academic PR, 1963.

39. Miranda, L.F. Estudo de parâmetros de processo para síntese de membranas hidrofílicas a base de poli (N-Vinil-2-Pirrolidona). 1999. Tese (Doutorado) - Instituto de Pesquisas Energéticas e Nucleares, São Paulo.

40. BOLETINS TÉCNICOS DA POLIALDEN, Março,1998.

41. AMERICAN SOCIETY FOR TESTING AND MATERIALS. Standard test method for tensile properties of plastics. (ASTM D 638)

42. AMERICAN SOCIETY FOR TESTING AND MATERIALS. Standard test method for density and specific gravity. (ASTM D 792) 
43. AMERICAN SOCIETY FOR TESTING AND MATERIALS. Standard test method for hardness shore. (ASTM D 2240)

44. INTERNATIONAL STANDARD ORGANIZATION (ISO). Standard test method for charpy impact strenght. (ISO 11542-2b)

45. ASSOCIAÇÃO BRASILEIRA DE NORMAS TÉCNICAS (ABNT). Ensaios para resistência a abrasão. (NBR 14922)

46. MACHADO, L.D.B. Aplicações da análise térmica à caracterização de polímeros. In: $4^{\circ}$ Seminário das Comissões Técnicas da Associação Brasileira de Polímeros, 31 de maio e

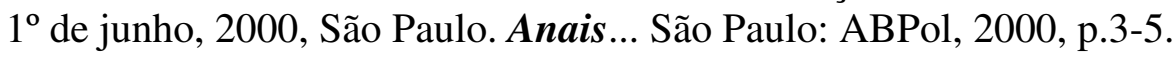

47. BILLMEYER, F.W. Textbook of polymer science. 2.ed. New York, N.Y.: John Wiley \& Sons, 1984.

48. TURI, E. Thermal Characterization of Polimeric Materials. New York, N.Y.: Academic Press, 1981.

49. AMERICAN SOCIETY FOR TESTING AND MATERIALS. Standard test method for transition temperatures of polymers by thermal analysis. (ASTM D 3418-82). 